\title{
Excess mortality and COVID-19 in Sweden in 2020: A demographic account
}

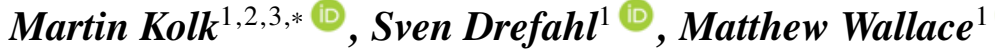 \\ and Gunnar Andersson ${ }^{1}$
}

\begin{abstract}
In this study, we provide an account of mortality levels in Sweden in 2020, focusing on both excess mortality and mortality due to COVID-19 deaths. We present various measures of life expectancy for women and men based on age-specific death rates in 2020. Our measures of excess mortality are based on comparisons with benchmarks derived from a previous mortality forecast for 2020 by Statistics Sweden and observed average mortality rates during 2017-2019. We present data on regional and seasonal variation in excess mortality, as well as estimates of Years of Potential Life Lost due to COVID-19. We decompose excess mortality in 2020 into excess mortality due to COVID-19 and excess mortality attributable to other causes. We also provide some estimates on the impact of excess mortality in 2020 on the remaining life expectancy for different cohorts of women and men in Sweden. We demonstrate that the impact of COVID-19 mortality was concentrated at higher ages, and among men in particular. Conversely, some younger age groups experienced negative excess mortality. The mortality changes during 2020 caused life expectancy levels to revert back to those observed in 2018 for women and in 2017 for men.
\end{abstract}

Keywords: excess mortality; mortality; life expectancy; COVID-19; Sweden

\section{Introduction and background}

COVID-19 spread across the globe in early 2020, and reached Sweden in March 2020. For much of the remaining year, Sweden witnessed elevated mortality due

\footnotetext{
${ }^{1}$ Demography Unit, Department of Sociology, Stockholm University, Stockholm, Sweden

${ }^{2}$ Institute for Future Studies, Stockholm, Sweden

${ }^{3}$ Åbo Akademi, Vasa, Finland

${ }^{*}$ Correspondence to: Martin Kolk, martin.kolk@ sociology.su.se
} 
to mortality associated with COVID-19. Here, we assess the extent of pandemicinduced excess mortality observed in 2020 . We provide a comprehensive breakdown of mortality due to COVID-19, as well as of overall excess mortality in Sweden by age, sex, calendar time and region.

In a very short time, the research world has produced an extensive body of work on various aspects of the COVID-19 pandemic and its consequences. Demographers have produced estimates of the impact of COVID-19 on mortality for a number of countries, including the United States (Andrasfay and Goldman, 2021; Goldstein and Lee, 2020), England and Wales (Aburto et al., 2021a) and Spain (Trias-Llimós et al., 2020). A comparative study by Aburto et al. (2021b) presented life expectancy estimates for 2020 for 29 countries, including Sweden, with mortality rates from 2019 used as a benchmark. The results showed that most of these countries experienced excess mortality, with a decline in life expectancy of up to 1.5 years, and with larger declines occurring among men than among women. Based on this benchmark, Sweden had slightly higher excess mortality than the median of the countries in the study, which may be attributable in part to an unusually pronounced mortality reduction in Sweden in 2019. A study by Pifarré i Arolas et al. (2021) calculated years of life lost in 2020 for 81 countries, and found that Sweden, like many other high-income countries, had a high concentration of mortality at older ages, with fewer years of life lost than if deaths had occurred at younger ages. Islam et al. (2021) estimated total excess mortality in 2020 for 29 high-income countries, and found that Sweden ranked in the middle of the 29 countries. Nevertheless, several countries had mortality levels in 2020 that were similar to or lower than their mortality levels in 2019, including the other Nordic countries of Denmark, Finland and Norway.

Some researchers have extolled the advantages of using excess mortality as a summary measure of the pandemic's effects in terms of elevated mortality, observing that it is a simple and objective measure that is particularly appropriate when comparing mortality differentials between countries (Beaney et al., 2020; Modig et al., 2020). Excess mortality is also suitable for measuring the effects of the pandemic in countries that lack high-quality registration of causes of death, which is not the case in Sweden, where death registration is of high quality and is virtually complete. Nonetheless, even for Sweden, using the extent of excess mortality as a summary measure of the impact of the COVID-19 pandemic on mortality patterns is of interest to researchers, not least in order to place the findings of investigations of the effects of the pandemic on mortality in the context of international research and earlier mortality patterns in Sweden.

Several studies conducted in Sweden have examined patterns of COVID-19related mortality based on individual-level data on observed deaths and causes of deaths during the early months of 2020. These studies found that mortality increased, most notably among socioeconomically disadvantaged groups (Drefahl et al., 2020), people living in crowded and multigenerational households (Brandén et al., 2020) and migrants (Aradhya et al., 2021; Rostila et al., 2021). Similar studies on mortality among foreign-born populations have been conducted in 
Norway (Indseth et al., 2020) and Belgium (Vanthomme et al., 2021). CalderónLarrañaga et al. (2020) showed that mortality in Stockholm was elevated in areas with lower incomes and/or in areas with more foreign-born residents. Modig et al. (2021a) investigated how mortality varied over different weeks throughout the year based on data up to week 33 (early August), and revealed the magnitude of excess mortality during the 2020 spring peak in Swedish mortality. Modig et al. (2021b) went on to report strongly elevated mortality among women and men living in elderly care homes within Sweden.

Throughout 2020, Sweden's COVID-19 response was regularly highlighted as an outlier relative to those of other European countries, as fewer restrictions were imposed on everyday life in Sweden than elsewhere. This issue was covered widely, and often critically, in international media (Simons, 2020). Among the crucial differences between Sweden and many other European countries were that in Sweden, primary schools, restaurants and shops were never closed; and mask-wearing was uncommon and was not mandated throughout 2020. However, working from home was very common for white-collar workers (Baral et al., 2021; Ludvigsson, 2020). In general, social distancing was encouraged through publicoriented guidelines rather than through policy-enforced mandates (Baral et al., 2021). Here, we also provide a regional comparison of mortality patterns within Sweden. However, there were no important regional differences in policy responses to COVID-19. While regional travel was discouraged during some periods, no travel restrictions were enforced (Ludvigsson, 2020).

There was a decrease in life expectancy for men and women in Sweden in 2020 that was, of course, due to the impact of COVID-19. In the remainder of our study, we demonstrate how this decrease (Section 3.1) was reflected by mortality changes in different age groups of women and men (Section 3.2), different months of the year (Section 3.3) and different regions of Sweden (Section 3.4). Furthermore, we show the extent to which the changes in life expectancy can be attributed to registered COVID-19 deaths, and to any remaining excess or reduced mortality from other causes of death in different age groups (Section 3.5). We conclude by estimating how excess mortality in 2020 affected measures of cohort life expectancy (Section 3.6). To our knowledge, such a comprehensive review of excess mortality for a country in 2020 has not previously been produced, although similar reviews for other countries will likely be available in the future.

Our study differs from previous studies on the levels and patterns of excess mortality in several ways. In particular, we compare the observed mortality in 2020 with the predictions from a pre-pandemic mortality forecast for 2020 produced by Statistics Sweden. Moreover, we primarily use the forecasted mortality rates for 2020 as our baseline, instead of the observed mortality during one or several prepandemic years, which can also be used as a baseline to which we compare any mortality deviations during the pandemic (e.g., Aburto et al., 2021b; Islam et al., 2021). Our approach has two advantages. First, it accounts for the secular trend of falling mortality that has been observed in most developed countries, including in Sweden (Drefahl et al., 2014). Simply using a pre-pandemic average of mortality 
rates as a benchmark could overestimate the mortality that would have occurred in the absence of COVID-19, and produce levels of excess mortality during 2020 that are unrealistically low. Second, the forecasted mortality values are based on the Lee-Carter method for extrapolation (described in Statistics Sweden, 2018) based on data for a longer time period that runs up to the time just before the outbreak of the pandemic, which produces more stable rates than those derived from shorter extrapolation windows. However, the use of this approach could also turn into a disadvantage if a new trend needs to be given more weight than it is given in the Lee-Carter design. Thus, we also compare the observed mortality patterns during 2020 with those of an observed average for the years 2017-2019, as this approach has been standard in much of the previous literature, and is necessary for describing dimensions of mortality change that are not considered in the forecasts of Statistics Sweden.

\section{Data and method}

\subsection{Data}

The following analyses are based on information from two different data sources. Our measures that use the number of deaths and the population numbers in different subgroups are derived from Statistics Sweden's population statistics, which provided us with ordered data on deaths and population size at the regional and monthly levels for the years 2017 to 2020, including the pandemic year. We supplemented this information with data from Statistics Sweden's official population forecast for 2020 onward (Statistics Sweden, 2020a). We attach the data delivered to us by Statistics Sweden as a supplemental file (available at https://doi.org/10. 1553/populationyearbook2022.res2.2). Other demographic data can be downloaded freely from Statistics Sweden's data repository website, including data on all of the rates they used for their population forecasts. In the discussion section, we briefly relate our estimates to those based on other recent data sources, such as the Human Mortality Database series on Short-Term Mortality Fluctuations (STMF).

Additionally, the Swedish Public Health Agency has provided us with data on COVID-19-related deaths. These data are based on the agency's collection of data on diseases covered by the Swedish Communicable Diseases Act, SmiNet (National Board of Health and Welfare, 2020a; Public Health Agency, 2021a). The reporting of such deaths is based on information on individuals who had received a positive test result for COVID-19. This information has since been combined with statistics on all deceased individuals from the Swedish Tax Agency's register, which serves as a basis for the population register. If a person dies within 30 days of receiving a laboratory-confirmed positive test result, he or she is counted as having died from COVID-19. Some sorting is done for individuals with causes of death that were clearly unrelated to COVID-19 (for example, traffic accidents), but as a rule, data on causes of death are not used in this data source. Individuals who 
die more than 30 days after receiving a confirmed positive COVID-19 test result, or who have never tested positive for COVID-19, are not included in the data material. According to the Public Health Agency, these reporting practices have resulted in some cases of people who actually died from COVID-19, but who had not been registered as having a positive test result, not being counted as having died from COVID-19 (Public Health Agency, 2021a). Unlike our demographic data from Statistics Sweden, the raw data on COVID-19 deaths cannot be shared due to ethical restrictions, but all rates and estimates based on these data are available upon request.

The definition of the number of COVID-19-related deaths differs somewhat from the cause-of-death-based statistics produced by the Swedish National Board of Health and Welfare. We have access to both of these data sources, and briefly evaluate the differences in outcomes between those sources in our appendix. While each of these sources has strengths and weaknesses, they are in broad agreement, and would produce results similar to those presented here.

When reporting non-COVID-19-related deaths, we use data on the total number of deaths in a given population group minus the COVID-19-related deaths for the same population group.

\subsection{Method}

With the help of data from the Swedish Public Health Agency and Statistics Sweden, we base our analyses on the observed number of deaths and the population size for each age in 2020. We have received comparable data from Statistics Sweden for 2017-2019. We have created life tables based on the data for 2020 and the average of the data for the preceding three years. We also use age-specific death rates from Statistics Sweden's forecast for 2020. We rely on period-based life tables for most of our calculations. For our calculations with five-year age groups, we use the weighted average of the death risks in one-year age groups. We close our life tables at age 100.

For our decomposition of the changes in life expectancy, we use a method introduced by Arriaga (1984) where ${ }_{n} \Delta_{x}$ is the contribution to the difference in life expectancy between population 1 and 2 from all-cause mortality in age group $x$ to $x+n$. The method is based on the conventional life table functions $l_{x}, T_{x}$, and ${ }_{n} L_{x}$.

$$
{ }_{n} \Delta_{x}=\frac{l_{x}^{1}}{l_{0}^{1}} \cdot\left(\frac{{ }_{n} L_{x}^{2}}{l_{x}^{2}}-\frac{{ }_{n} L_{x}^{1}}{l_{x}^{1}}\right)+\frac{T_{x+n}^{2}}{l_{0}^{1}} \cdot\left(\frac{l_{x}^{1}}{l_{x}^{2}}-\frac{l_{x+n}^{1}}{l_{x+n}^{2}}\right)
$$

We expand the decomposition with:

$$
{ }_{n} \Delta_{x}^{i}={ }_{n} \Delta_{x} \cdot \frac{{ }_{n} R_{x}^{i}(2) \cdot{ }_{n} m_{x}(2)-{ }_{n} R_{x}^{i}(1) \cdot{ }_{n} m_{x}(1)}{{ }_{n} m_{x}(2)-{ }_{n} m_{x}(1)}
$$

where the ${ }_{n} \Delta_{x}^{i}$ is the contribution to the difference in life expectancy for the cause of death $i$ in age group $x$ to $x+n$, and the contribution this cause of death makes to the difference in life expectancy between the two populations. ${ }_{n} m_{x}(1)$ and ${ }_{n} m_{x}(2)$ 
represent the death rate for age group $x$ to $x+n$, and ${ }_{n} R_{x}^{i}(1)$ and ${ }_{n} R_{x}^{i}(2)$ represent the proportion of deaths from the cause of death $i$ for age group $x$ to $x+n$ in the two populations. As was described in the first equation, ${ }_{n} \Delta_{x}$ is the difference in mortality from all causes of death in age group $x$ to $x+n$.

In Section 3.5, we use the Years of Potential Life Lost (YPLL) method. YPLL is calculated according to Equation (3) below, where $d_{x}$ is the number of deaths at age $x$ (in our case, COVID-19 deaths in 2020), and $e_{x}$ is the remaining life expectancy at age $x$ (in our case, according to Statistics Sweden's forecast), which is summed up over all ages. The limitations and the implicit and explicit assumptions of this method are described by Gardner and Sanborn (1990). The aim of this method is to quantify the extent of a change that negatively affects mortality at the population level.

$$
Y P L L=\sum_{x}^{\infty} d_{x} \cdot e_{x}
$$

In our study, we also make forecasts of how excess mortality in 2020 has affected cohort life expectancy in Sweden using information on future mortality patterns based on the official Swedish population forecasts. For our cohort life expectancy table, which we present in Section 3.6, we use the death rates for 2020 linked to the population projection for 2020-2070 (Statistics Sweden, 2020a). A more detailed description of how these projections were generated is available in Statistics Sweden's (2020a) population forecasts. In our case, we calculate cohort life expectancy tables in which we compare the impact of the observed mortality in 2020 with that of the forecasted mortality for the same year, while keeping the forecasted death rates for 2021 onward intact. In other words, we examine how a single year of excess mortality in 2020 affects cohort life expectancy, assuming that the death rates in future years will be neither higher nor lower than the death rates that were forecasted before the pandemic. We show changes in life expectancy for men and women who had reached ages 55, 65, 75, 85 and 95 in 2020. Our calculations are based on the population numbers observed at the end of 2019. ${ }^{1}$

In the next section, we first discuss the life expectancy trends in Sweden over recent decades, and then describe the changes in life expectancy for women and men in Sweden in 2020. We start by placing excess mortality in 2020 in a slightly longer-term context (2000-2020). We then discuss the patterns in mortality changes in 2020 by age and sex, and the patterns in excess mortality by calendar-year month during 2020, when COVID-19-related deaths were concentrated in AprilMay and November-December. Next, we explore the regional impact of COVID-19 deaths, examining the excess mortality patterns by region (or county) of residence in Sweden. Finally, we decompose excess mortality in 2020 by the contributions

\footnotetext{
1 Note that these numbers refer to those individuals who reached a certain age in 2020, as this information is included in the rates used by Statistics Sweden in their forecasts. The numbers do not refer to everyone born in a single year, but rather to those born in the second half of a given year and the first half of the subsequent year.
} 
of changes in the age-specific mortality rates and in registered causes of death. We also calculate a metric based on years of potential life lost. Finally, by combining mortality data from 2020 and cohort projections of future life expectancy, we estimate the impact of COVID-19 during 2020 on the remaining life expectancy for selected cohorts of women and men in Sweden. These analyses combined provide one of the most comprehensive overviews of the effects COVID-19 on mortality in a country, in Sweden or elsewhere.

\section{Results}

\subsection{Changes in life expectancy and number of deaths}

Life expectancy has increased steadily over the past century for women and men in developed societies, including in Sweden (Wilmoth et al., 2000; Christensen et al., 2009). However, the increases in the most recent decades in Sweden have been somewhat slower than the increases observed many other European countries. This has mainly been due to mortality at the very highest ages declining more slowly in Sweden than in other countries considered to be global life expectancy leaders (e.g., Drefahl et al., 2014). However, mortality rates at older ages for men and at younger ages for both women and men are still lower in Sweden than they are in most other countries (Drefahl et al., 2014). In 2019, a near unprecedented reduction in mortality was observed in Sweden. In the context of an average annual increase in life expectancy in recent decades of 0.1-0.2 years, life expectancy in 2019 increased by half a year for both men ( 0.56 years) and women ( 0.48 years).

Following this positive development, 2020 was the first year in a long time indeed, since 1968 - in which a substantive decline in life expectancy occurred in Sweden. Compared to 2019, life expectancy decreased in 2020 by 0.69 years for men and by 0.40 years for women. In Statistics Sweden's previous population forecast for 2020 based on assumptions made prior to the pandemic, life expectancy in 2020 was estimated to be 0.78 years (for men) and 0.43 years (for women) higher than the values that were actually observed. Thus, Statistics Sweden's forecast of life expectancy for 2020 was only marginally higher than the observed life expectancy for 2019.

In Table 1 and Figure 1, we show the development over time of life expectancy at birth, alongside residual life expectancies at ages 65 and 85, separately for men and women. Life expectancy at birth was 84.33 years for women and 80.66 years for men in 2020, or 0.46 and 0.78 years lower than Statistics Sweden's forecasted values of 84.79 and 81.44 years for the same year. The differences were about the same size for remaining life expectancy at age 65 , while they were slightly smaller for life expectancy at age 85. As can be seen in Figure 1, life expectancy in 2020 was similar to 2018 levels for women, and was similar to 2017 levels for men (see Figure 1). Thus, mortality in Sweden in 2020 reverted to the higher mortality levels documented several years earlier. 
Table 1:

Life expectancy at birth, age 65 and age 85 in Sweden, for 2019, 2020 and the forecast for 2020

\begin{tabular}{lccccc}
\hline & $\begin{array}{c}\mathbf{2 0 1 9} \\
\text { Life expectancy }\end{array}$ & $\begin{array}{c}\mathbf{2 0 2 0} \\
\text { observed }\end{array}$ & $\begin{array}{c}\mathbf{2 0 2 0} \\
\text { observed }\end{array}$ & $\begin{array}{c}\mathbf{2 0 2 0} \\
\text { minus } \\
\text { forecast }\end{array}$ & $\begin{array}{c}\mathbf{2 0 2 0} \text { observed } \\
\text { minus 2020 } \\
\text { forecast }\end{array}$ \\
\hline Women & & & & & \\
$\quad$ From birth (e0) & 84.73 & 84.33 & 84.79 & -0.40 & -0.46 \\
From 65 (e65) & 22.00 & 21.50 & 21.97 & -0.50 & -0.48 \\
From 85 (e85) & 7.11 & 6.72 & 7.03 & -0.40 & -0.32 \\
Men & & & & & \\
From birth (e0) & 81.35 & 80.66 & 81.44 & -0.69 & -0.78 \\
From 65 (e65) & 19.52 & 18.93 & 19.62 & -0.59 & -0.69 \\
From 85 (e85) & 5.93 & 5.48 & 5.91 & -0.45 & -0.43 \\
\hline
\end{tabular}

Figure 1:

Life expectancy at birth, age 65 and age 85 in Sweden, for 2000-2020, and the forecast for 2020

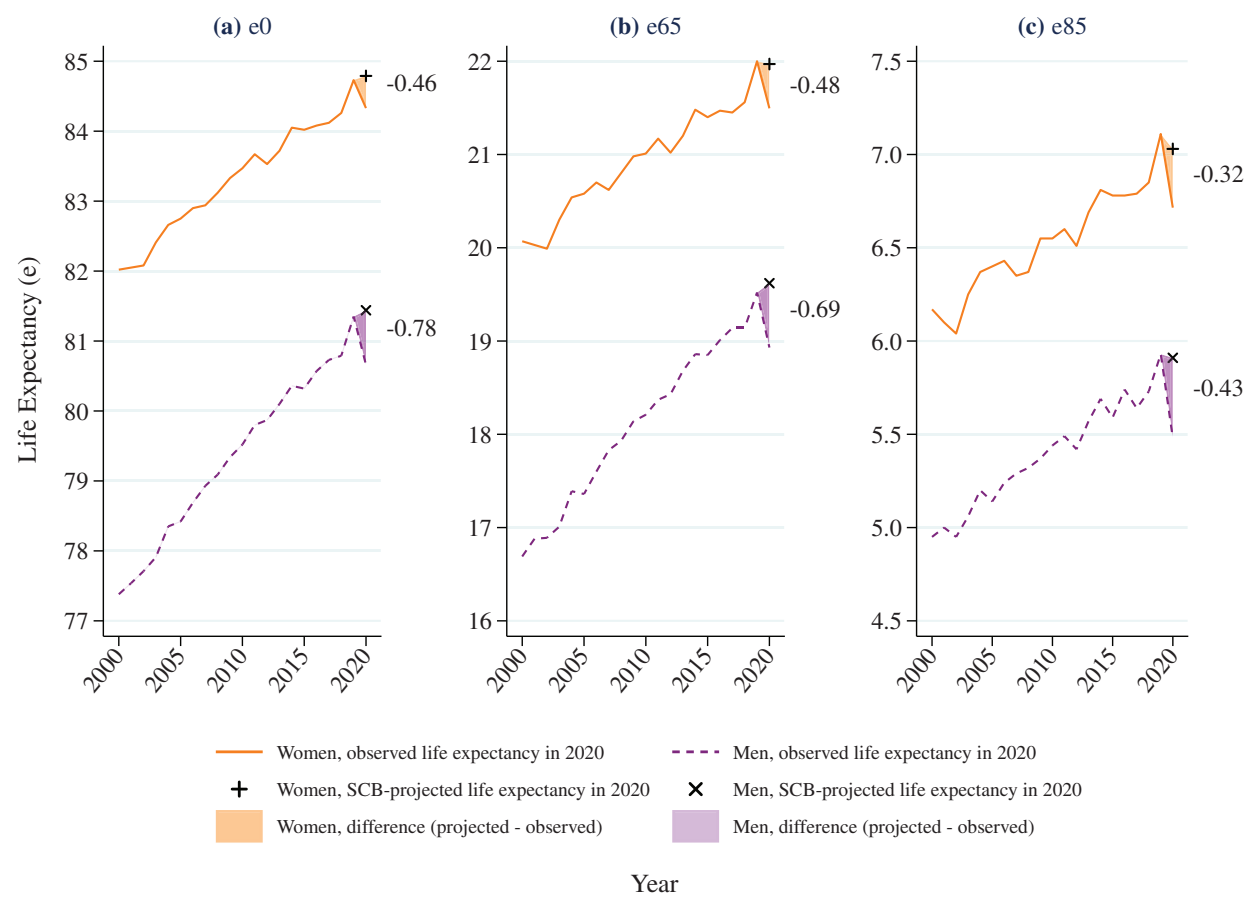


Figure 2:

Death rates per 1,000 inhabitants in Sweden, 2000-2020, and the 2020 forecast

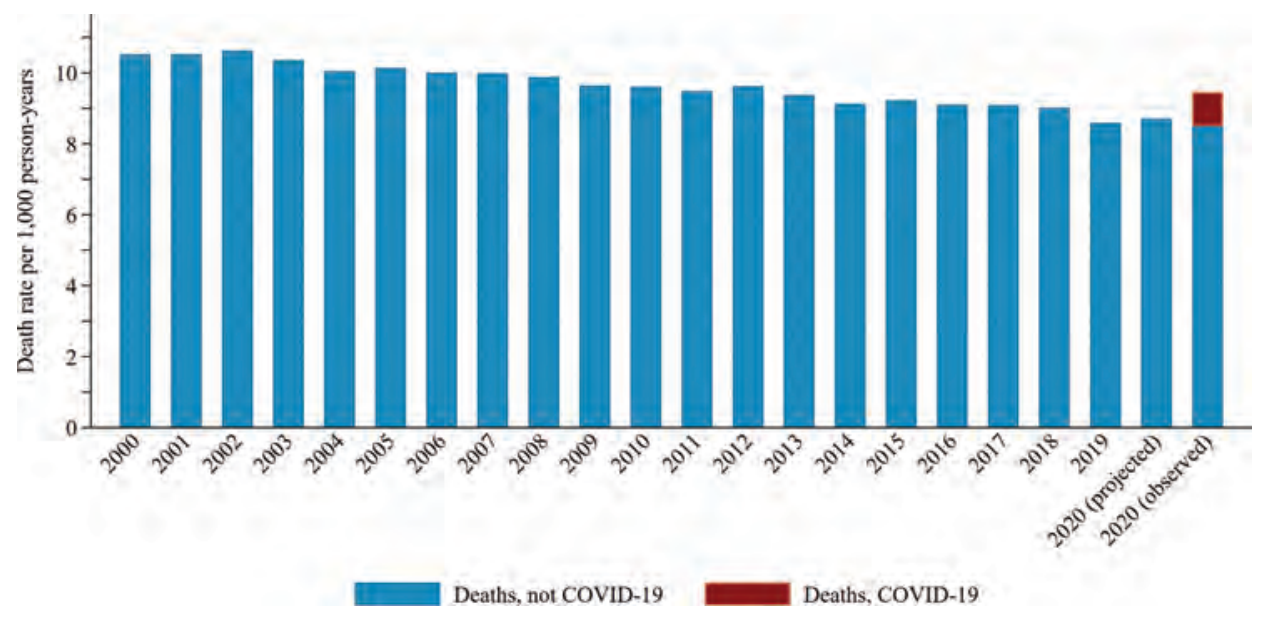

In Figure 2, we show crude death rates calculated as the number of deceased persons in Sweden per calendar year during 1990-2020 in relation to the size of the population in each year. The figure provides the mortality per 1,000 individuals in 2020, including the portion that was due to COVID-19 mortality. The latter value is based on data on COVID-19 deaths provided by the Swedish Public Health Agency.

Figure 2 shows the same declining trend in overall mortality over time that was reported in Figure 1. However, these death rates are the product of two counteracting forces: the effects of declining mortality in each age group and the gradual aging of the Swedish population. Thus, the crude death rates per 1,000 individuals in the population are affected by changes in the population size through childbirth and migration, and also by changes in the population age structure through variations in cohort sizes among older men and women. In the short term, however, the changes in the population structure are small, and comparisons of the crude rates remain valid. For 2020, the crude death rate was 8.6 percent higher than the rate that had been forecasted by Statistics Sweden; it was 10.0 percent higher than the rate that was observed for 2019; and it was 4.9 percent higher than the rate that was observed for 2018. If we remove the number of deaths associated with COVID-19 from the total, the crude mortality rate is 2.3 percent lower than the rate that had been forecasted by Statistics Sweden. However, such a figure should be interpreted while taking into account that the number of deaths not associated with COVID-19 is not unrelated to the number of deaths associated with COVID-19. Consequently, the figure is likely overestimated.

The impact of COVID-19 played a slightly larger role in the development of the crude death rate during 2020 (Figure 2) than in the expected life expectancy 
(Figure 1). This is because many COVID-19 deaths occurred at old ages, and thus did not affect remaining life expectancy as much as the increase in the absolute number of deaths itself would suggest. In the rest of our study, we focus primarily on analyses of changes in age-specific death rates, as well as calculations of the remaining life expectancy based on those death rates. A major advantage of relying on measures such as life expectancy at different ages is that they measure mortality that is independent of the age structure of a population, which is important when comparing mortality measures for different years and countries.

\subsection{Age-specific death rates}

In this section, we examine age variation in mortality patterns in 2020 . We first present the number of deaths for different age groups during the calendar year in Table 2. We show separately the number of COVID-19 deaths and all deaths combined in the different age groups. At ages below 30, the number of COVID-19 deaths was very small (eight for women and 14 for men). The number of deaths was, as expected, highest at the older ages, regardless of whether the deaths were from COVID-19 or from other causes. During the year, the total number of COVID19-related deaths was 9,816, while the total number of deaths from all causes was 98,124 . Thus, 10.0 percent of all deaths in 2020 were from COVID-19. The COVID19 deaths were even more strongly concentrated at older ages than deaths in general. The proportion of deaths from COVID-19 was higher among men than among women in all age groups from age 40 onward.

We then present the age-specific death rates for women and men in 2020 (Figure 3), which reflect the risk of dying during the year for individuals in different age groups. The figure has an exponential scale (whereby the distance between two scale lines in the figure corresponds to a 10 -fold increase in mortality) to better showcase the patterns and the large differences in the risk of dying by age. The figure clearly shows that COVID-19-related mortality and mortality in general increase very sharply with age. For example, the age-specific death rate for men aged 40-44 years was 0.000043 deaths per person-year for COVID-19 and 0.000954 deaths per person-year for total mortality, while the respective values for women aged 60-64 years were 0.00019 and 0.00472 , and the respective values for men aged 85-89 years were 0.017 and 0.136 . The figure also shows that the share of COVID-19 deaths in total mortality is not the same across all ages, but is lowest at young ages, and is highest around ages 80-90.

As a next step, we compare the actual age-specific death rates for women and men in 2020 with the age-specific death rates that Statistics Sweden adopted in its latest forecast for 2020 and the average value of the observed death rates for 2017-2019 (Figure 4). We report the relative risk ratios: i.e., the difference in percent between the death rates as they appear in Figure 3 and those expected for 2020 in different age groups. Among older age groups, who experience significantly more deaths than younger age groups, an excess mortality rate of 10 percent leads to significantly 
Table 2:

Number of deaths in different age groups in Sweden, all-cause mortality and COVID-19 mortality, 2020

\begin{tabular}{|c|c|c|c|c|c|c|}
\hline \multirow[b]{2}{*}{$\begin{array}{l}\text { Age } \\
\text { group }\end{array}$} & \multicolumn{3}{|c|}{ Women } & \multicolumn{3}{|c|}{ Men } \\
\hline & $\begin{array}{c}\text { Deaths, } \\
\text { COVID-19 }\end{array}$ & $\begin{array}{l}\text { Deaths, } \\
\text { all causes }\end{array}$ & $\begin{array}{c}\text { Deaths from } \\
\text { COVID-19 } \\
\text { as a \% of } \\
\text { all deaths }\end{array}$ & $\begin{array}{c}\text { Deaths, } \\
\text { COVID-19 }\end{array}$ & $\begin{array}{l}\text { Deaths, } \\
\text { all causes }\end{array}$ & $\begin{array}{c}\text { Deaths from } \\
\text { COVID-19 } \\
\text { as a \% of } \\
\text { all deaths }\end{array}$ \\
\hline $0-29$ & 8 & 348 & 2.3 & 14 & 786 & 1.8 \\
\hline $30-34$ & 8 & 126 & 6.3 & 6 & 241 & 2.5 \\
\hline $35-39$ & 5 & 157 & 3.2 & 6 & 221 & 2.7 \\
\hline $40-44$ & 9 & 208 & 4.3 & 14 & 308 & 4.5 \\
\hline $45-49$ & 12 & 327 & 3.7 & 27 & 497 & 5.4 \\
\hline $50-54$ & 17 & 541 & 3.1 & 61 & 881 & 6.9 \\
\hline $55-59$ & 35 & 846 & 4.1 & 99 & 1458 & 6.8 \\
\hline $60-64$ & 53 & 1340 & 4.0 & 134 & 2170 & 6.2 \\
\hline $65-69$ & 106 & 2199 & 4.8 & 278 & 3461 & 8.0 \\
\hline $70-74$ & 267 & 4021 & 6.6 & 523 & 5692 & 9.2 \\
\hline $75-79$ & 482 & 5723 & 8.4 & 782 & 7699 & 10.2 \\
\hline 80-84 & 774 & 7469 & 10.4 & 1104 & 8639 & 12.8 \\
\hline $85-89$ & 1153 & 9716 & 11.9 & 1118 & 8750 & 12.8 \\
\hline 90-94 & 1041 & 9806 & 10.6 & 801 & 6270 & 12.8 \\
\hline 95-99 & 484 & 4912 & 9.9 & 276 & 2065 & 13.4 \\
\hline $100+$ & 90 & 1004 & 9.0 & 29 & 243 & 11.9 \\
\hline In total & 4544 & 48743 & 9.3 & 5272 & 49381 & 10.7 \\
\hline
\end{tabular}

more additional deaths than the corresponding relative excess mortality at younger ages. It appears that the observed mortality was higher than expected for men in all age groups starting at age 50, and for women in all age groups starting at age 70 . The relative excess mortality among older individuals was higher among men than it was among women. Excess mortality was higher if we place greater emphasis on the comparison with Statistics Sweden's forecast than on the comparison with the average values for the 2017-2019 period. Compared with Statistics Sweden's forecast, the relative excess mortality was just over 10 percent among men aged 50 and above, it was just under 10 percent among post-retirement-aged women.

For younger age groups, we observe both excess and reduced mortality in 2020 . The percentage variation between different years could be greater here, as the number of deaths was smaller. For men aged 30-49, we find reduced mortality in 2020, which could be explained by changes in behavior in response to various measures that may have discouraged different types of risky behavior. However, for women aged 30-49, we find the opposite pattern, with excess mortality being observed among women in their thirties. At very young ages, we also see some variation in relative excess and reduced mortality, with opposite patterns for men 
Figure 3:

Age-specific death rates, in five-year age groups in 2020 in Sweden, for all-cause and COVID-19 mortality
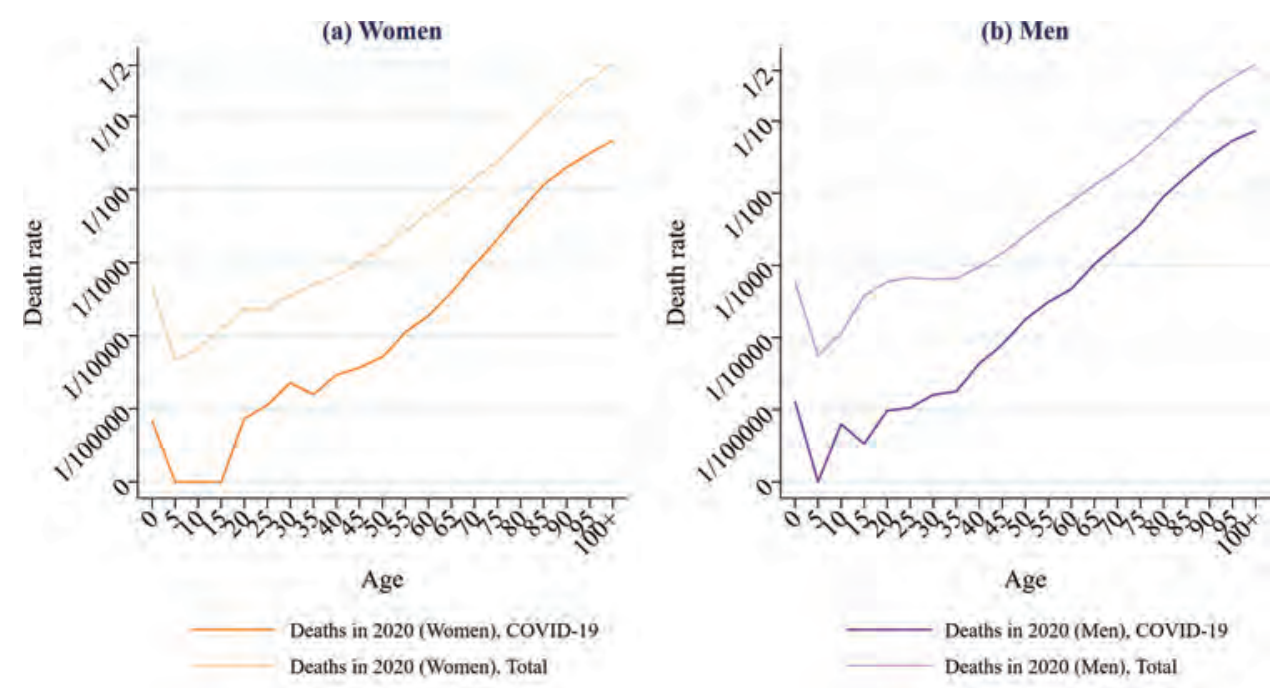

and women. For the very youngest age groups, the number of COVID-19 deaths was very small (Table 2), and the differences shown in Figure 4 may be due to variation in deaths from causes other than COVID-19. Mortality at these ages was so low that even a small number of deaths could lead to percentage changes in such comparisons.

\subsection{Seasonal variation in mortality}

The impact of COVID-19 was unequally distributed over 2020, with a first wave of deaths occurring in April-May 2020, and a second wave occurring in NovemberDecember 2020. Elevated mortality was also observed in January 2021. However, these deaths are not considered in this study. We show the monthly mortality trends in 2020 in Figure 5. Specifically, we present the monthly death rate per 100,000 person-years in four broad age categories (0-29, 30-64, 65-84 and 85+). We compare the death rates per month in 2020 (the solid orange line) with the observed average death rates per month for the average of 2017-2019 (the dashed orange line). Here, unfortunately, we are unable to provide comparisons with any forecasts, as Statistics Sweden does not produce such monthly forecasts. The shaded areas represent the differences between these two rates. Dark orange indicates that mortality was higher in a given month in 2020 than in the 2017-19 average, while light orange indicates that mortality was lower in a given month in 2020 than in the 2017-19 average. The purple line shows the death rate per 1,000 person-years 
Figure 4:

Relative differences in observed mortality 2020 compared with the 2020 forecast, and the average of 2017-2019, for different age groups of women and men in Sweden
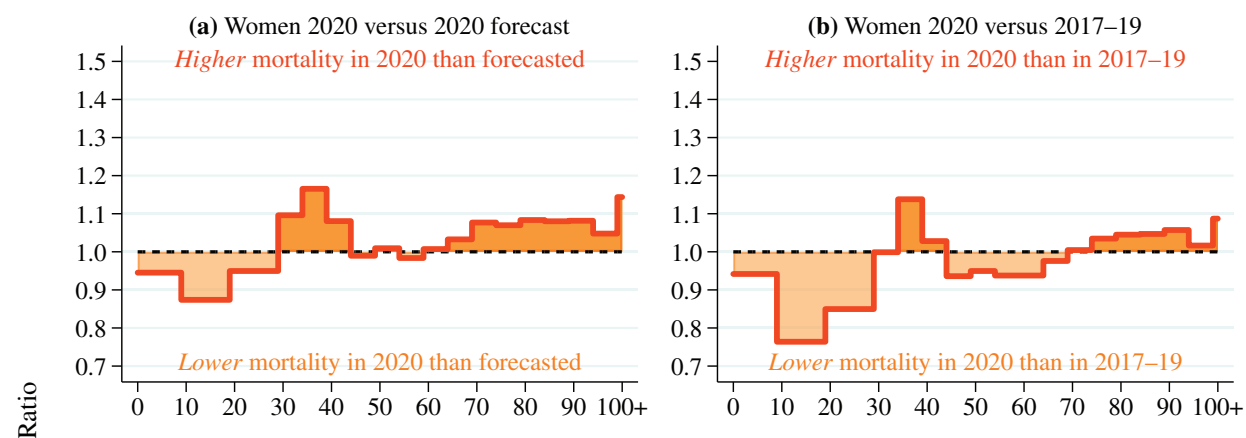

(c) Men 2020 versus 2020 forecast

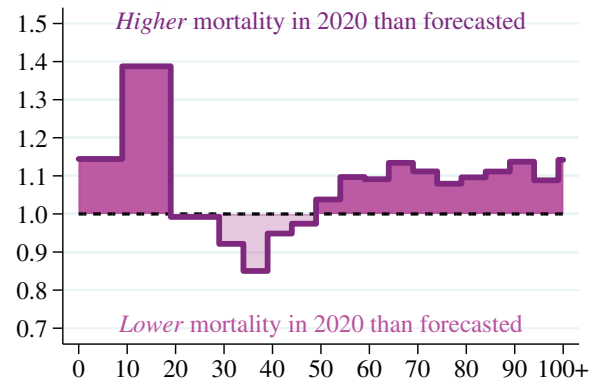

(d) Men 2020 versus 2017-19

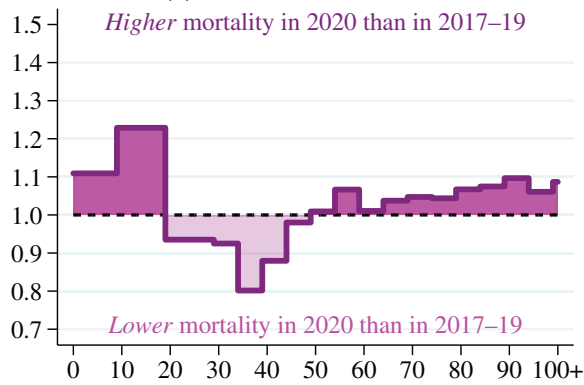

Age

from COVID-19. Note the differences in scale across the age-specific panels. Here, at least visually, we can only make comparisons within the four panels, rather than across the panels.

Figure 5 shows that the impact of COVID-19 on total mortality in Sweden in 2020 was largest in the months of April, May (i.e., the peak of the first wave of the pandemic in Sweden), November and December (i.e., the start of the second wave), especially in the 65-84 and 85+ age groups. As expected, the trends in excess mortality in 2020 compared to the 2017-19 average closely track the fluctuations that we observe in mortality from COVID-19. Thus, larger blocks of dark orange, indicating excess mortality in 2020, correspond with higher mortality rates from COVID-19. For the 65-84 and 85+ age groups, we observe a similar or even greater impact of COVID-19 mortality on overall mortality in the second wave than in the first wave. This pattern can be seen in both the magnitude of the mortality rate from COVID-19 and the magnitude of the overall excess mortality in 2020. However, for the 30-64 age group, the mortality rate from COVID-19 was lower around the end of 2020 than it was in spring 2020. Thus, for this age group, we find excess mortality driven by COVID-19 in April and May only. We can only speculate why this was 
Figure 5:

Death rates by month during 2020, by age group in Sweden, for the average of 2017-2019 and for 2020: all-cause and COVID-19 deaths

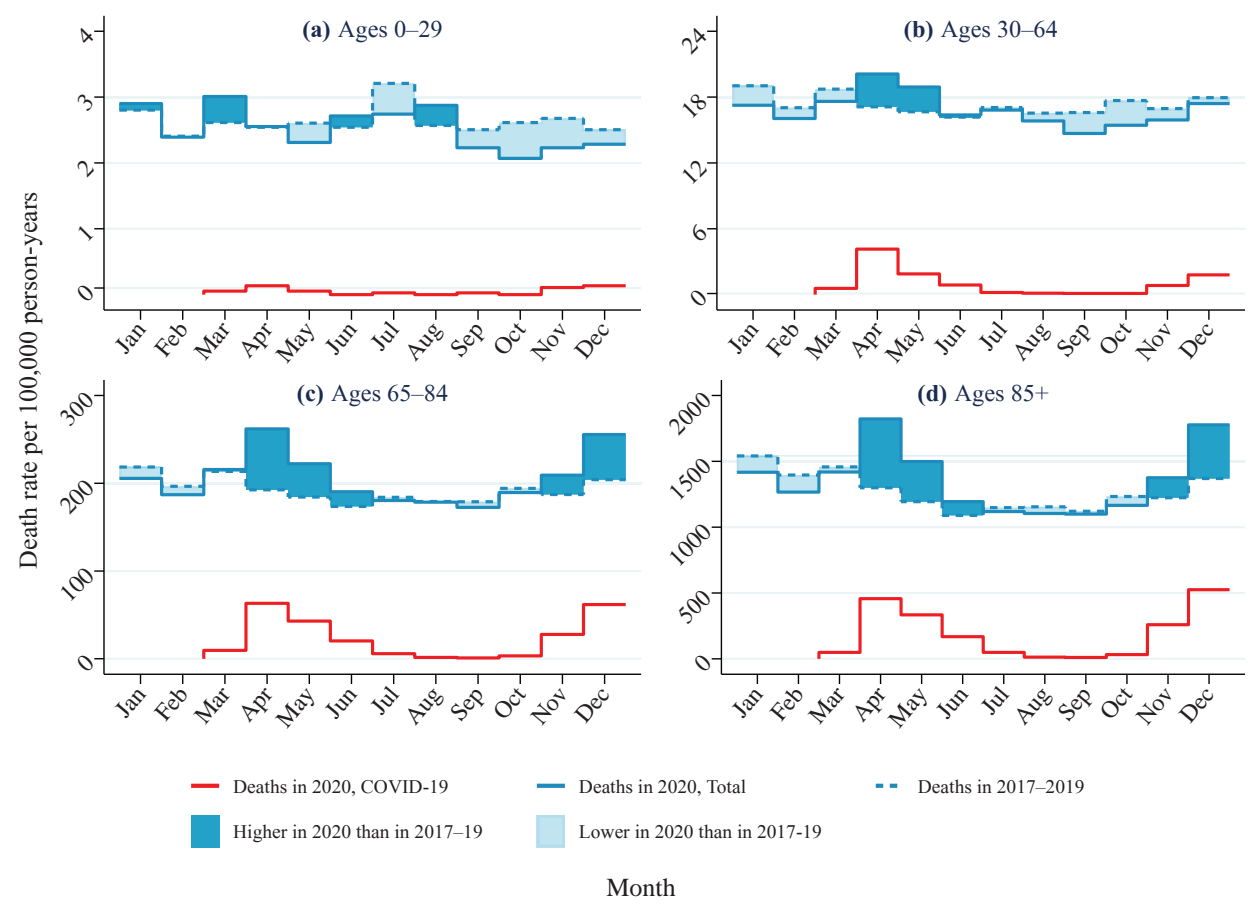

the case given the limits of our data, but one partial explanation could be that hospital treatments for COVID-19 became more effective over the year (National Board of Health and Welfare, 2020b). For the youngest age group (0-29), we find more fluctuations in excess mortality, including in the months in which COVID-19 mortality was actually the lowest (e.g., June and August). The number of COVID19 deaths in this age group was very small, and the age range covers very different stages of mortality. These factors may explain why the pattern observed for this age group differs from that for other age groups.

\subsection{Regional differences in mortality changes}

Figures 6(a) and 6(b) show the impact of mortality from COVID-19 at the regional level. Here, our aim is to investigate whether COVID-19 had a similar or differential impact across counties in Sweden. The COVID-19 epidemic has had an unequal impact on different regions of Sweden, with the first phase of the pandemic being concentrated in the Stockholm region. It has been suggested that population density 
Figure 6(a):

Life expectancy $\left(e_{0}\right)$ at birth in different regions of Sweden for 2017-2019 and 2020: Change in life expectancy
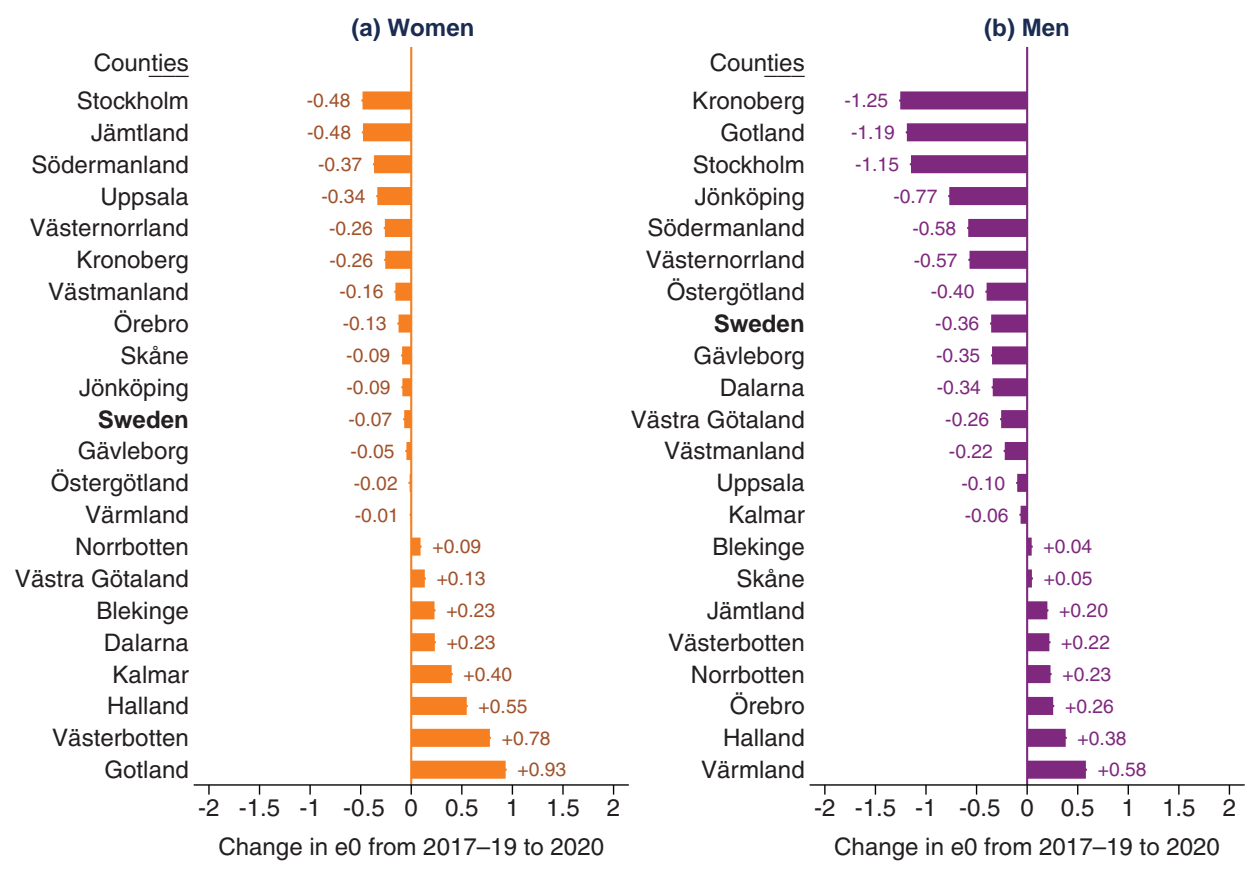

is a determinant of COVID-19 transmission (Quast et al., 2020). In Sweden, the highest population densities are found in the urban conglomerations centered around Stockholm, Gothenburg (Västra götaland) and Malmö (Skåne). Figure 6(a) shows the change in life expectancy at birth (from now on, $e_{0}$ ) between 2020 and the 2017-2019 average (i.e., $e_{0}$ in 2020 minus $e_{0}$ for the average of the years 2017-19) for women (panel a) and for men (panel b) in Sweden's 21 counties. A three-year reference period is necessary to obtain more stable comparisons when analyzing regions that have significantly fewer inhabitants than Sweden as a whole. Moreover, Statistics Sweden does not conduct forecasts at the county level. Our three-year average is based on a higher mortality baseline than that of the forecast, which illustrates the differences between the two approaches (and the advantages of using a reliable forecast as a comparison). Within both of the panels, the counties are ordered from those that were the most negatively impacted by COVID-19 (top) to that were the least - or not at all - negatively impacted by COVID-19 (bottom). As an additional comparator for the counties, we include the same metric for all of Sweden. In Figure 6(c), we include a map.

At the country level, $e_{0}$ in 2020 in Sweden was 0.07 years shorter among women and was 0.36 years shorter among men compared to the 2017-2019 average. At 
Figure 6(b):

Life expectancy $\left(e_{0}\right)$ at birth in different regions of Sweden for 2017-2019 and 2020: Ranking of counties by life expectancy
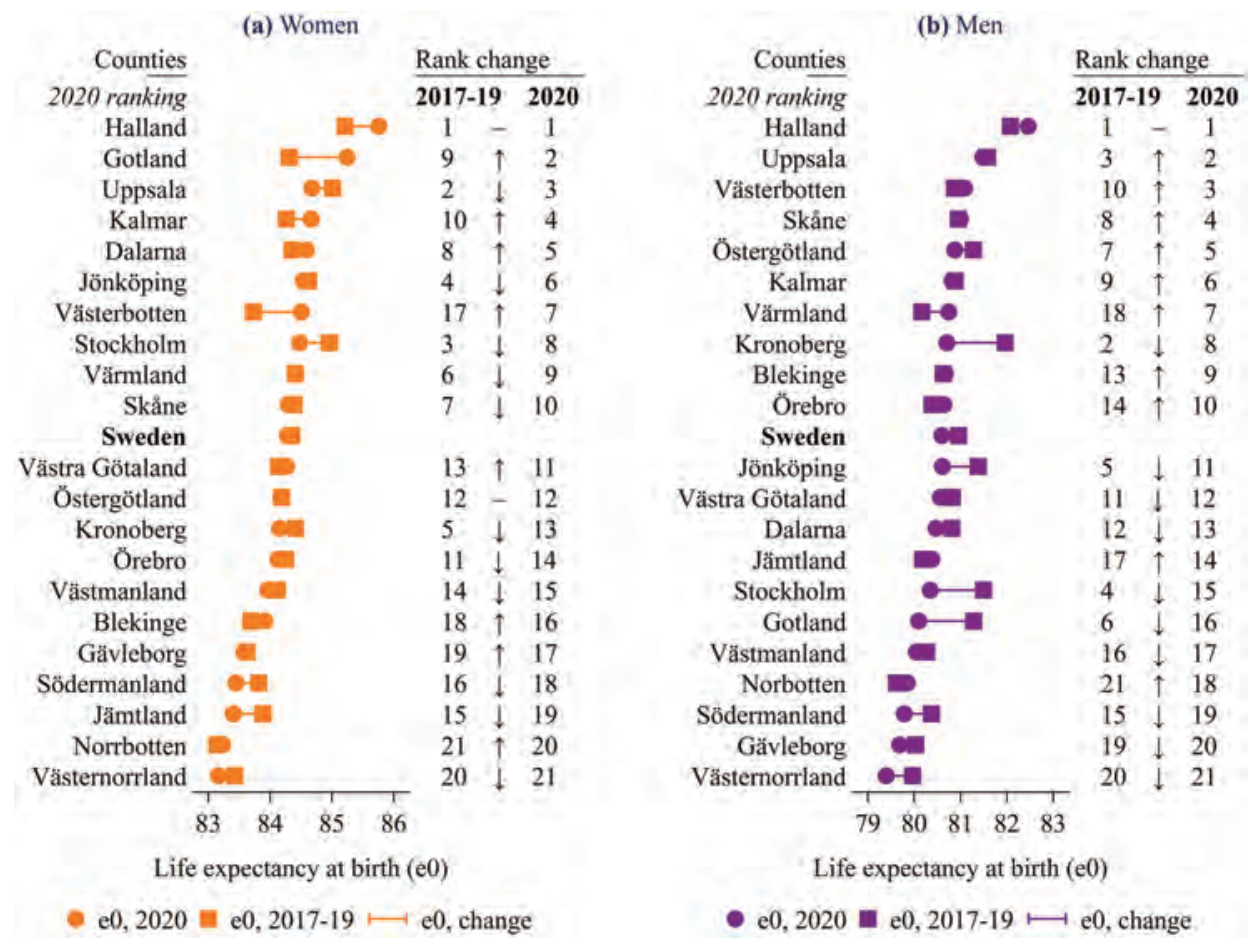

the regional county level, we document substantial geographical variation in the impact of COVID-19, with the impact being much greater or much smaller on the populations of some counties than on the total population. We also find a significant amount of within-county variation by sex. However, we highlight the counties where the direction of the effect was similar for men and women. Some of our regions are quite small, with the populations of the counties at the end of 2020 ranging from 60,124 in Gotland to 2,391,990 in the Stockholm region, with a median value of slightly below 300,000. Among the issues that can arise when studying mortality changes in smaller regions is the impact of random variation (e.g., Scherbov and Ediev, 2011; Eayres and Williams, 2004).

Men in 14 counties experienced a decline in $e_{0}$ in 2020 relative to 2017-19, while men in seven counties experienced an increase. The changes in $e_{0}$ for men ranged from a decrease of 1.25 years in Kronoberg to an increase of 0.58 years in Värmland. Women in 12 counties experienced a decline in $e_{0}$, while women in nine counties experienced an increase. The changes in $e_{0}$ for women ranged from a decrease of 0.48 years in Stockholm to an increase of 0.93 years in Gotland. Among both sexes, Stockholm, Västernorrland, Kronoberg and Södermanland were 
Figure 6(c):

Map of regional changes in life expectancy $\left(e_{0}\right)$ at birth in different regions of Sweden for 2017-2019 and 2020

(a) Women

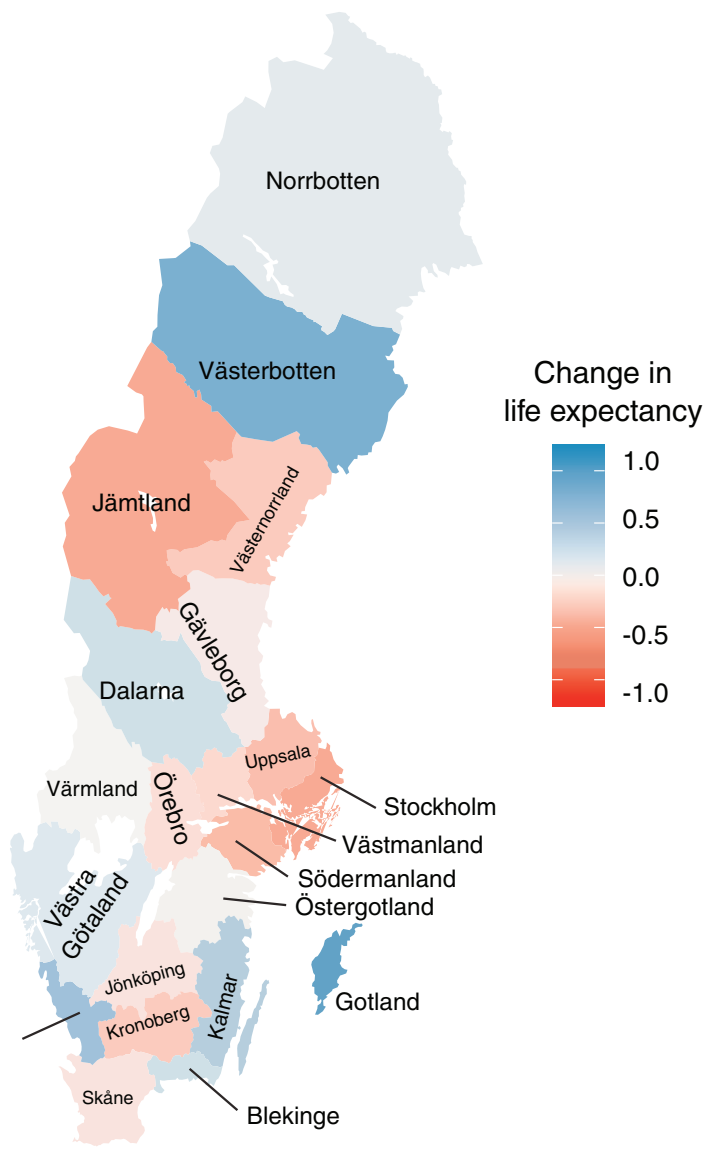

(b) Men

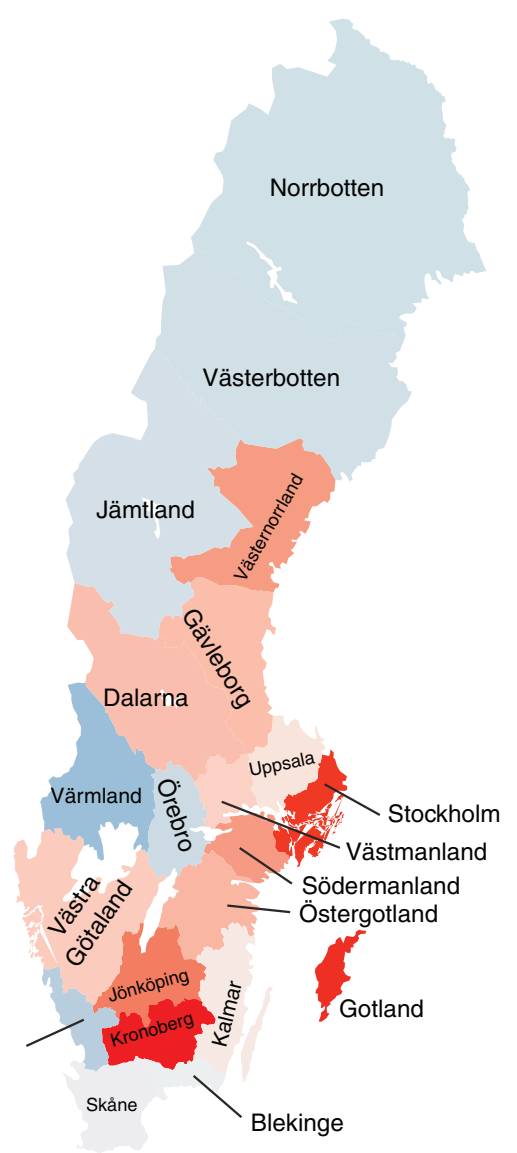

some of the worst affected counties, with $e_{0}$ for men and women declining in 2020 compared to 2017-19. Halland and Västerbotten were some of the least affected counties, with $e_{0}$ increasing for men and women in 2020 compared to 2017-19. However, as we alluded to above, the direction of the impact on $e_{0}$ was not always the same for men and women. The clearest example is in Gotland, where $e_{0}$ for men declined by 1.19 years (making it one of the worst affected counties for men), while $e_{0}$ for women rose by 0.93 years (making it the least affected of all counties for women). There were three other counties where $e_{0}$ for women increased while $e_{0}$ for men decreased: namely, Kalmar, Dalarna and Västra Götaland. Conversely, there were four counties where $e_{0}$ increased for men while $e_{0}$ decreased for women: 
namely, Skåne, Jämtland, Örebro and Värmland. It is unclear exactly why COVID19 mortality had a differential impact on men and women in the same county. While investigating this unexpected pattern is beyond the scope of this study, it may reflect noise in the estimates (especially for some of the smaller counties, including Gotland) or county- and sex-specific COVID-19 risk factors.

Figure 6(b) plots and ranks counties by their $e_{0}$ in 2020, and thus puts the magnitude of the losses or gains from Figure 6(a) in a wider perspective. Counties are ordered from those with the highest $e_{0}$ in 2020 (top) to those with the lowest $e_{0}$ in 2020 (bottom) for women (a) and men (b). As we can see, Halland retains its position as Sweden's most longevous county. This is unsurprising given that Figure 6(a) shows that between 2020 and 2017-19, $e_{0}$ increased by 0.55 years among women and by 0.38 years among men. Uppsala also retained its position as one of Sweden's most longevous counties, even though $e_{0}$ in the county decreased by 0.38 years among women and by 0.10 years among men. The rank change for Stockholm, previously one of Sweden's most longevous counties in 2017-19, was stark, with the county falling from third to eighth place for female $e_{0}$, and from fourth to 15 th place for male $e_{0}$. We also find that some counties rose in these mortality rankings. Most notably, Västerbotten, which was formerly ranked 17th for $e_{0}$ for women and 10th for $e_{0}$ for men, rose to seventh place for female $e_{0}$ and to third place for male $e_{0}$. These rank changes were due to increases in $e_{0}$ between 2020 and 2017-19 of 0.78 years among women and 0.22 years among men. COVID19 had the most disproportionate impact on Stockholm county in 2020.

In Figure 6(c), we map the decline in $e_{0}$. The figure confirms that the life expectancy reductions were higher in eastern Sweden than western Sweden, and it shows that neighboring regions and regions with strong transport links to Stockholm also had lower $e_{0}$ in 2020. Overall, the decline in life expectancy was most evident in Stockholm, its neighboring counties, Småland and the southern parts of the Norrland coast. The regions that were least affected by excess mortality were in western and southern Sweden and in upper Norrland. Overall, mortality was high in Stockholm, in line with its high population density; and was low in the most sparsely populated regions of Sweden. On the other hand, the two other densely populated counties in Sweden, Västra Götaland and Skåne, had below-average mortality during the year. A transmission-based explanation for the spread of COVID-19 in Sweden during 2020 - i.e., that the virus spread earlier and led to higher mortality in Stockholm and in regions with travel and migration networks centered around Stockholm than in more remote regions - may fit the regional patterns in mortality differentials better. We can see no clear regional socioeconomic pattern in excess mortality, even though mortality in the relatively wealthy region of Stockholm has been concentrated in the more vulnerable areas (Calderón-Larrañaga et al., 2020). However, the regional patterns of excess mortality have also changed during the course of the pandemic, not just in 2020, but in 2021. Stockholm was hit more severely in the early phase of the pandemic, while many regions that were less affected during the spring of 2020 were more affected during the pandemic's second and third waves that took place in late 2020 and early 2021. This changing geographical landscape of the pandemic 
within Sweden beyond 2020 resembles the fluctuations in the timing and the severity of COVID-19 waves that have been observed in other countries in Europe and across the world during the pandemic years of 2020 and 2021.

\subsection{The impact of age-specific changes in mortality on period life expectancy}

As a next step, we explore how changes in age-specific mortality during 2020 have contributed to the life expectancy changes in 2020, using an Arriaga decomposition approach as described in our methods section. In panels a and c of Figure 7, we present a breakdown of the contributions of different age groups to the total differences in life expectancy between the actual values observed for 2020 and the values that were forecasted for 2020 by Statistics Sweden. We show here the positive or the negative contributions to the reduced $e_{0}$ in 2020 ( -0.79 years for men and -0.46 years for women) due to mortality changes in different five-year age groups of women and men. It is clear from Figure 7 that the decline in $e_{0}$ in 2020 was mostly due to increased mortality among men over age 55 and among women over age 70 . For men, we note a positive contribution to $e_{0}$ due to mortality reductions among younger adult men. We also observe a minor negative contribution to $e_{0}$ due to increased mortality among boys, which can probably be attributed to random variation between different years, rather than to COVID-19. For women, we see few deviations in mortality in addition to the clear deviations that can be observed for the older age groups.

In panels $\mathrm{b}$ and $\mathrm{d}$ of Figure 7, we provide the same breakdown of differences in $e_{0}$, but with separate accounts of the contributions of COVID-19-related mortality and mortality from other causes. The contributions of COVID-19 mortality were always negative, while the contributions of mortality from other causes could be either negative or positive. The sum of the various bars gives the total difference between the actual $e_{0}$ in 2020 and the $e_{0}$ that was forecasted by Statistics Sweden for the same year.

The direct contributions of COVID-19-related mortality can mainly be attributed to increased mortality at older ages. For mortality that cannot be attributed to COVID-19, we see that the levels were mainly lower than expected. However, it is complicated to divide up different causes of death in this way because people who died of COVID-19 could not die of other causes during the year. Moreover, some of the reduced mortality in causes of death other than COVID-19 may be attributable to various behavioral changes, such as fewer traffic accidents or reductions in the incidence of infectious diseases other than COVID-19.

However, we can still state that we do not see any increased mortality from causes other than COVID-19 in 2020, which suggests that hypothetical displacement effects in health care had not yet significantly affected mortality in that year (Sprung et al., 2020). Moreover, the potential underreporting of COVID-19-related deaths 
Figure 7:

Decomposition of the differences between the actual life expectancy in Sweden in 2020 the forecasted life expectancy for 2020 (in years), with positive and negative contributions of mortality changes in different age groups. Decomposition of all-cause mortality in panels a and $c$, and decomposition by type of mortality in panels b and d

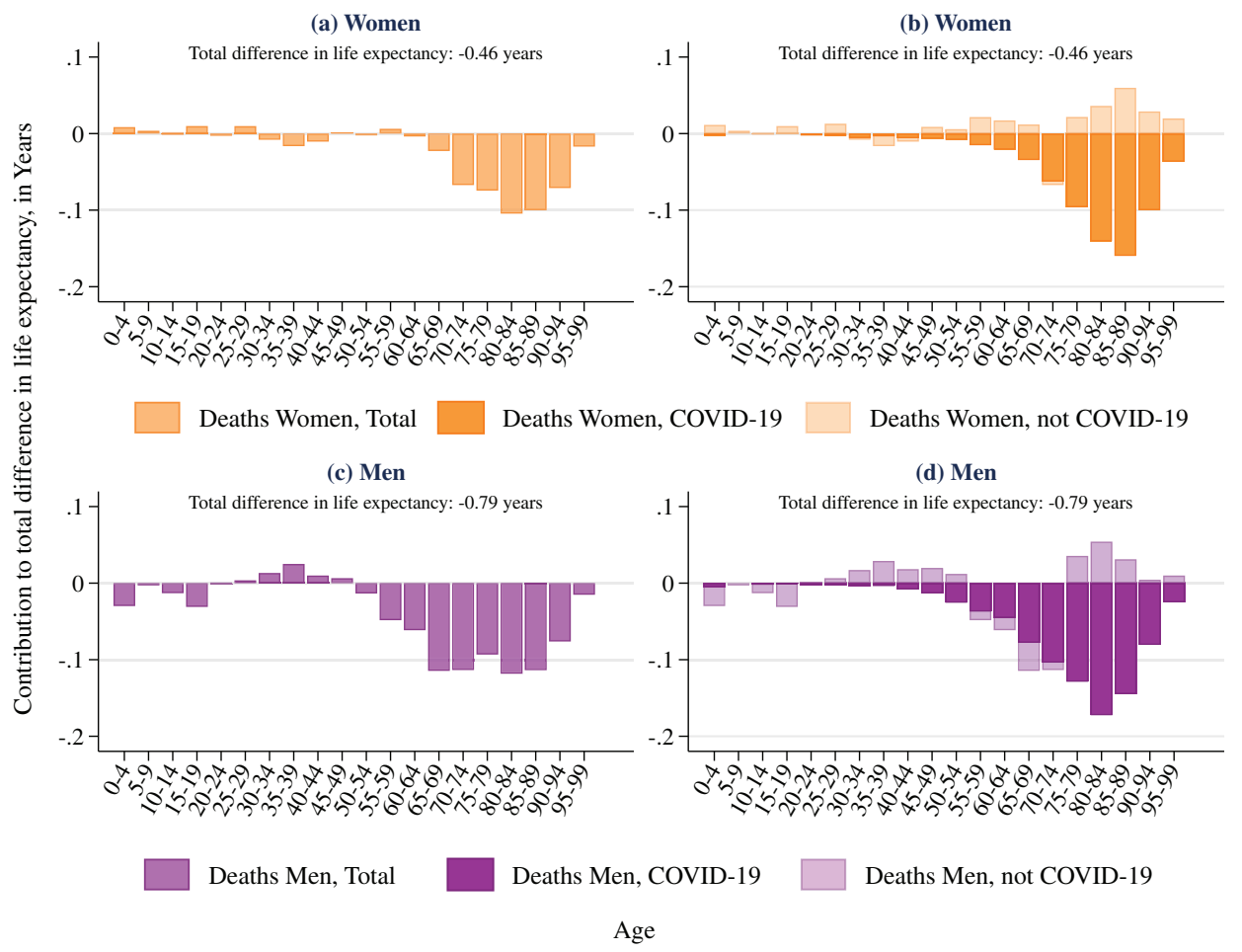

(see appendix) could not have contributed to the patterns we observe for other types of mortality, which are shown in Figure 7.

In Figure 8, we present the Years of Potential Life Lost (YPLL) due to deaths from COVID-19 in 2020. This metric provides an alternative view, placing greater importance on the time lost than on the number of deaths. The time lost is based on the difference between the age at death and the maximum potential lifespan of a person at that age (and the summation of the differences). To illustrate, a girl who dies just after birth is assumed to have lost a potential 84.79 years of life (as per Figure 1), while a 65-year-old man who dies is assumed to have lost a potential 19.62 years of life (as per Figure 1). YPLL places greater weight on deaths that occur at younger ages, but crucially acknowledges that all deaths imply some loss of life (Gardner and Sanborn, 1990; Martinez et al, 2019). This is relevant given that some policy responses have been framed around the argument that COVID-19 
Figure 8:

Years of Potential Life Lost (YPLL) attributed to deaths from COVID-19 in 2020, for women and men in Sweden by one-year age groups

(a) Women

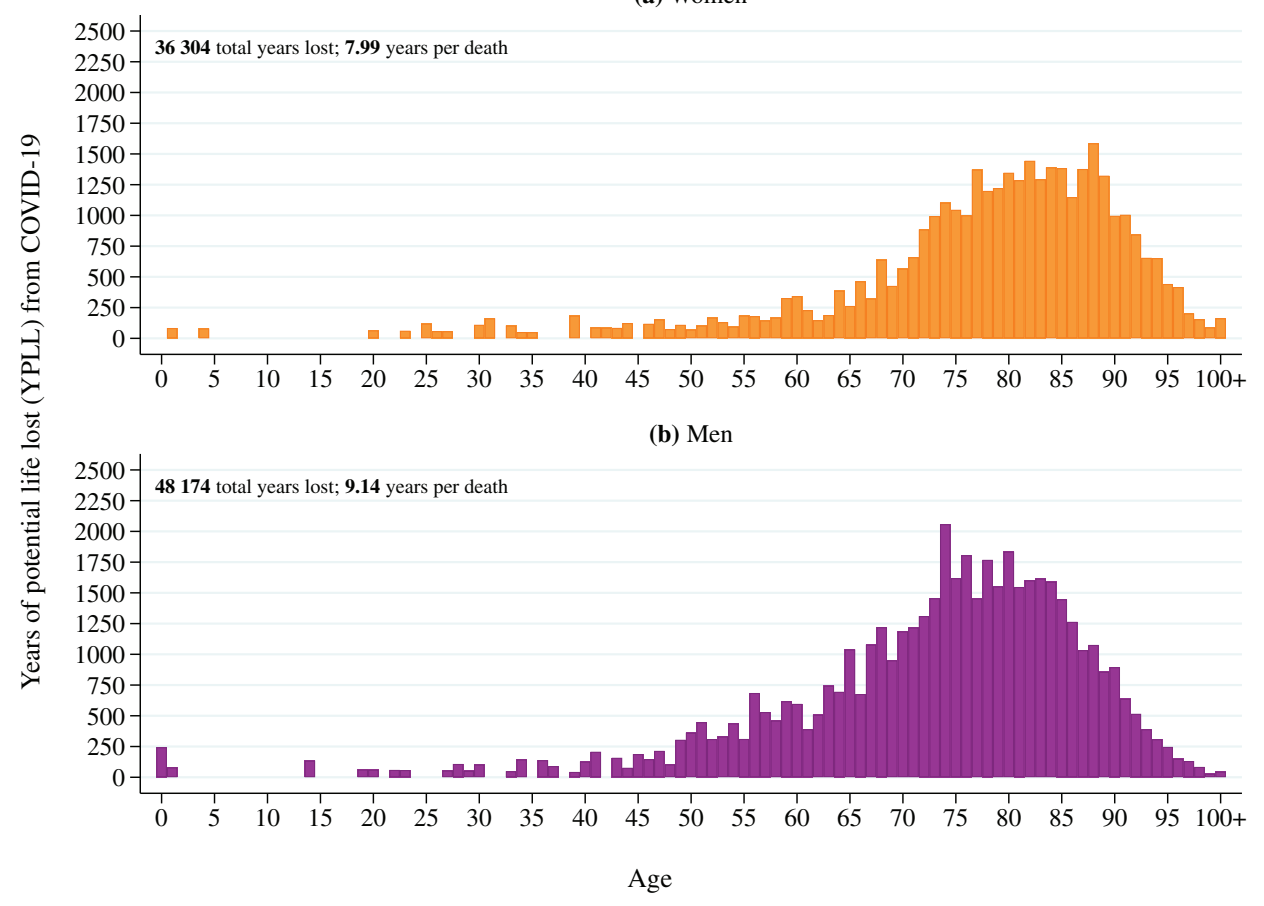

mortality has mostly affected people who, even in the absence of COVID-19, would have died soon anyway from other causes (Pifarré i Arolas et al., 2021).

As Figure 8 shows, COVID-19 can be linked to 48,174 lost years of life for men and 36,304 lost years of life for women in Sweden. These values correspond to an average of 9.14 years lost per male death from COVID-19 and 7.99 years lost per female death from COVID-19. Regarding the distribution of the years of life lost, if we adopt the age groups defined in previous analyses, we find that men aged $0-29,30-64,65-84$ and $85+$ accounted for $2 \%, 20 \%, 60 \%$ and $18 \%$ of YPLL, respectively. Among women, the same age groups accounted for around $1 \%, 12 \%$, $52 \%$ and $35 \%$ of YPLL, respectively. Thus, we can see that more potential years of life were lost at younger ages among men. Indeed, a fifth of all YPLL among men were concentrated between ages 30 and 64 (mostly at the upper end of this range). This is a not an insignificant share given that the death rates in this age group were lower than those in the older age groups. However, despite the greater weights placed on young deaths, $78 \%$ of all male YPLL and $87 \%$ of all female YPLL were attributed to deaths in the $65+$ age groups. From a public health standpoint, these 
results provide an aggregated statistic on the degree to which life has been cut short in the Swedish population by COVID-19.

\subsection{The impact of mortality on cohort life expectancy}

Finally, we use a novel cohort approach to estimate how excess mortality in 2020 may have affected the remaining lifespan for selected birth cohorts of women and men in Sweden. We provide in Table 3 an estimate of how excess mortality in 2020 may have affected the remaining life expectancy for people in Sweden who were alive at different ages at the beginning of 2020. To do so, we use a so-called cohort life expectancy table and assumptions about future mortality patterns derived from Statistics Sweden's population forecast for 2021 onward, as described in the methods section. We compare the observed mortality in 2020 with the forecasted mortality for the same year, while retaining the forecasted mortality rates for the years 2021 onward. With this method, we estimate how much the increased mortality in 2020 affected the cohort life expectancy for men and women of different ages. Therefore, Table 3 shows the effects of COVID-19 mortality on remaining life

Table 3:

Changes in remaining life expectancy due to mortality changes at different ages during 2020, based on cohort life tables. Differences between the impact of observed mortality and forecasted mortality for 2020

\begin{tabular}{|c|c|c|c|c|c|c|}
\hline Sex & $\begin{array}{l}\text { Remaining life } \\
\text { expectancy/ } \\
\text { Number of } \\
\text { people in life }\end{array}$ & $\begin{array}{c}\text { Turned } \\
55 \text { years } \\
\text { old in } \\
2020\end{array}$ & $\begin{array}{c}\text { Turned } \\
65 \text { years } \\
\text { old in } \\
2020\end{array}$ & $\begin{array}{l}\text { Turned } \\
75 \text { years } \\
\text { old in } \\
2020\end{array}$ & $\begin{array}{l}\text { Turned } \\
85 \text { years } \\
\text { old in } \\
2020\end{array}$ & $\begin{array}{c}\text { Turned } \\
95 \text { years } \\
\text { old in } \\
2020\end{array}$ \\
\hline & $\begin{array}{l}\text { Remaining life expectancy } \\
\text { (years) with forecasted death } \\
\text { rates }\end{array}$ & 33.58 & 23.66 & 14.72 & 7.46 & 3.21 \\
\hline \multirow[t]{2}{*}{ Women } & $\begin{array}{l}\text { Remaining life expectancy } \\
\text { (years) with observed death } \\
\text { rates }\end{array}$ & 33.58 & 23.65 & 14.70 & 7.42 & 3.15 \\
\hline & $\begin{array}{l}\text { Remaining life expectancy } \\
\text { (years) with forecasted death } \\
\text { rates }\end{array}$ & 31.38 & 21.55 & 12.91 & 6.28 & 2.71 \\
\hline \multirow[t]{2}{*}{ Men } & Remaining life expectancy & 31.37 & 21.53 & 12.88 & 6.20 & 2.64 \\
\hline & & Age 55 & Age 65 & Age 75 & Age 85 & Age 95 \\
\hline Women & Population, end of 2019 & 68104 & 54350 & 54018 & 16221 & 1956 \\
\hline Men & Population, end of 2019 & 69700 & 53745 & 51059 & 23265 & 5361 \\
\hline
\end{tabular}


expectancy using an approach that, unlike those used in our previous sections, is not based on the synthetic cohorts for a single calendar year.

We show that the impact was relatively limited for 55- and 65-year-olds, but note that the effects were greater for people who were aged 85 years and older. At the age of 95 , the average remaining life expectancy is relatively short (slightly more than three years for women and a little less than three years for men). It is estimated that due to the increased mortality in 2020, more than 5,000 95-year-old women had their lives shortened by an average of 21 days. The corresponding figure for 95 -yearold men was 24 days. Among 85-year-olds, the average remaining life expectancy was shortened by 16 days for women and by 27 days for men. For 75 -year-olds, the reduction in the average remaining life expectancy was seven days for women and 11 days for men, while for 65-year-old men, it was nine days. For 65-year-old women and 55-year-old men and women, the average reduction in life expectancy was less than a few days. To put our estimates into context, we note that the difference in the remaining life expectancy at age 65 for cohorts born between 1910 and 1920 was around 0.1 additional year per single birth year (Statistics Sweden, 2020b). Put differently, each subsequent cohort lived around 0.1 years (around five weeks) longer after age 65 than the cohort before them. Hence, for the oldest cohorts shown in Table 3, who turned age 85 and age 95 in 2020, the actual reduction in remaining life expectancy in 2020 (compared to the pre-pandemic forecast for Sweden) was around 0.04-0.08 years (around 2-4 weeks). The observed decline in cohort life expectancy was thus comparable in size to around half of a one-year cohort improvement in life expectancy. For those aged 55 to 75 years, the decline was smaller.

\section{Conclusions}

In our study, we examined the impact of the COVID-19 pandemic on mortality patterns in Sweden during the calendar year 2020. We found that the pandemic reversed recent gains in life expectancy in Sweden, causing period life expectancy to revert to levels last observed during the years 2017-2018. It is unusual for life expectancy to decrease to any significant extent between calendar years. The last time a significant decline in life expectancy levels for both sexes had been seen in Sweden was in 1968, although the decline in that year was less pronounced than the decrease in 2020.

The increase in mortality in Sweden in 2020 was concentrated among the older age groups, while some of the younger age groups had lower mortality than expected. Men were hit harder than women. Because the mortality increases were heavily concentrated at older ages, their impact on various age-adjusted mortality measures, such as remaining life expectancy, was smaller than the increases in the number of actual deaths would suggest. However, 2020 was indeed an unusual mortality context, as the COVID-19 pandemic led to 7,752 more deaths than had been forecasted for that year. Mortality was highest in April and December of 2020. 
Our study makes several novel contributions to research on the impact of COVID19 on overall mortality change. We focused on Sweden, a country that has received an unusual amount of attention for its COVID-19 policy response during the course of the pandemic. We provided a multifaceted account of the impact of COVID-19 on patterns of mortality change during 2020. Unlike most previous studies on this topic, we mainly used data based on forecasted mortality rates as the baseline for comparison when calculating our measures of excess mortality. While this approach has advantages as well as disadvantages, we consider a forecasted baseline to be a more plausible hypothetical counterfactual scenario than a baseline derived from the average of a few pre-pandemic years. Finally, we provide estimates of how the excess mortality in 2020 has affected the cohort life expectancy of men and women in Sweden.

Like in most other high-income countries, COVID-19 had a tangible influence on excess mortality in Sweden during 2020 (Aburto et al., 2021b; Achilleos et al., 2021; Pifarré i Arolas et al., 2021). As in other countries, the impact was greater at the older ages, and was larger among men than among women (Aburto et al., 2021b; Islam et al., 2021). Compared to the mortality levels in 2019, excess mortality in Sweden in 2020 was slightly above the average for other countries with comparable data, and was certainly above the levels observed for the other Nordic countries, to which the situation in Sweden has been compared (Aburto et al., 2021b; Achilleos et al., 2021; Islam et al., 2021). Declines in life expectancy of 0.69 years for men and 0.40 years for women in Sweden can be compared to declines of around two years for men and more than 1.5 years for women in the United States (Aburto et al., 2021b); and to declines of 0.8 to 1.5 years in Spain, Italy, England and Belgium (Aburto et al., 2021b). By contrast, the Nordic countries neighboring Sweden had very low COVID-19-related mortality in 2020, with essentially no reductions in life expectancy between 2019 and 2020 (Aburto et al., 2021b). For their analysis of the effects of the pandemic in Sweden, Aburto et al. (2021b) relied on the Short-Term Mortality Fluctuations (STMF) data series (2021). Their results were largely similar to our own, although the STMF data for Sweden showed slightly higher mortality in 2020: i.e., they found a decline in life expectancy for 2020 that was around 0.1 years larger than the decline observed in our calculations. Explaining the differences and the similarities in mortality between Sweden and other countries is an important task for future research. If other countries produce data like those presented in our study, further comparisons of mortality patterns in which adjustments for the effects of different population age structures can be made will become possible.

Our study was limited to quantifying the influence of the pandemic during 2020. However, mortality associated with COVID-19 was also significant during the first two months of 2021 (Public Health Agency, 2021b), and small numbers of COVID19-related deaths have been reported throughout the spring, summer and autumn of 2021. As a consequence, Sweden may experience excess mortality in 2021 as well as in 2020. Furthermore, we currently lack knowledge about the possible long-term impact of COVID-19 on the health and mortality of the population. In addition, our aggregated data did not allow us to examine socioeconomic differences in outcomes, 
or differences between the native and the immigrant population (cf. Drefahl et al., 2020; Brandén et al., 2020; Rostila et al., 2021; Aradhya et al., 2021). COVID19 will continue to have an impact on different aspects of Sweden's demographic dynamics over the next few years. In 2020, COVID-19 mostly had an effect on the Swedish age structure through excess mortality at older ages. The extent to which the indirect effects of COVID-19 will (continue to) spill over to other demographic processes, such as those related to childbearing and international and domestic migration, remains to be seen.

\section{Supplementary Material}

Available online at https://doi.org/10.1553/populationyearbook2022.res2.2

Supplementary file 1 . Mortality by sex, age and county 2017-2020

\section{Acknowledgements}

We are grateful for financial support from the Swedish Public Health Authority, which partially financed the study; as well as for support from the Swedish Research Council for Health, Working Life, and Welfare (FORTE) for an aging research project, grant number 2016-07115. The funders of the study had no role in the study design, data analysis, data interpretation or writing of the report. The authors received funding from the Swedish Public Health Authority with a free and open mandate to write a (Swedish language) report on excess mortality in Sweden in early 2021.

\section{ORCID}

Martin Kolk (1) https://orcid.org/0000-0002-7175-4040

Sven Drefahl (D) https://orcid.org/0000-0003-4533-7558

Matthew Wallace (D) https://orcid.org/0000-0002-8318-7952

Gunnar Andersson (i) https://orcid.org/0000-0001-8900-8903

\section{References}

Aburto, J. M., Kashyap, R., Schöley, J., Angus, C., Ermisch, J., Mills, M. C., and Dowd, J. B. (2021a). Estimating the burden of the COVID-19 pandemic on mortality, life expectancy and lifespan inequality in England and Wales: A population-level analysis. Journal of 
Epidemiology and Community Health, 75, 735-740. https://doi.org/10.1136/jech-2020215505

Aburto, J. M., Schöley, J., Kashnitsky, I., Zhang, L., Rahal, C., Missov, T., Mills, M. C., Dowd, J. B., and Kashyap, R. (2021b). Quantifying impacts of the COVID-19 pandemic through life-expectancy losses: A population-level study of 29 countries. International Journal of Epidemiology, 26, Article dyab207. https://doi.org/10.1093/ije/dyab207

Achilleos, S., Quattrocchi, A., Gabel, J., Heraclides, A., Kolokotroni, O., Constantinou, C., Pagola Ugarte, M., Nicolaou, N., Rodriguez-Llanes, J. M., Bennett, C. M. et al. (2021). Excess all-cause mortality and COVID-19-related mortality: A temporal analysis in 22 countries, from January until August 2020. International Journal of epidemiology, Article dyab123. https://doi.org/10.1093/ije/dyab123

Andrasfay, T., and Goldman, N. (2021). Reductions in 2020 US life expectancy due to COVID-19 and the disproportionate impact on the Black and Latino populations. Proceedings of the National Academy of Sciences, 118(5), Article e2014746118. https://doi.org/10.1073/pnas.2014746118

Aradhya, S., Brandén, M., Drefahl, S., Obućina, O., Andersson, G., Rostila, M., Mussino, E., and Juárez, S. P. (2021). Intermarriage and COVID-19 mortality among immigrants: A population-based cohort study from Sweden. BMJ Open, 11(9), Article e048952. https://doi.org/10.1136/bmjopen-2021-048952

Arriaga, E. E. (1984). Measuring and explaining the change in life expectancies. Demography, 21(1), 83-96. https://doi.org/10.2307/2061029

Baral, S., Chandler, R., Prieto, R. G., Gupta, S., Mishra, S., and Kulldorff, M. (2021). Leveraging epidemiological principles to evaluate Sweden's COVID-19 response. Annals of epidemiology, 54, 21-26. https://doi.org/10.1016/j.annepidem.2020.11.005

Beaney, T., Clarke, J. M., Jain, V., Golestaneh, A. K., Lyons, G., Salman, D., and Majeed, A. (2020). Excess mortality: The gold standard in measuring the impact of COVID-19 worldwide? Journal of the Royal Society of Medicine, 113(9), 329-334. https://doi.org/10. 1177/0141076820956802

Brandén, M., Aradhya, S., Kolk, M., Härkönen, J., Drefahl, S., Malmberg, B., Rostila, M., Cederström, A., Andersson, G., and Mussino, E. (2020). Residential context and COVID-19 mortality among adults aged 70 years and older in Stockholm: A populationbased, observational study using individual-level data. The Lancet Healthy Longevity, 1(2), e80-e88. https://doi.org/10.1016/S2666-7568(20)30016-7

Calderón-Larrañaga, A., Vetrano, D. L., Rizzuto, D., Bellander, T., Fratiglioni, L., and Dekhtyar, S. (2020). High excess mortality in areas with young and socially vulnerable populations during the COVID-19 outbreak in Stockholm Region, Sweden. BMJ Global Health, 5(10), e003595. https://doi.org/10.1136/bmjgh-2020-003595

Christensen, K., Doblhammer, G., Rau, R., and Vaupel, J. W. (2009). Ageing populations: The challenges ahead. The Lancet, 374(9696), 1196-1208. https://doi.org/10.1016/S01406736(09)61460-4

Drefahl, S., Ahlbom, A., and Modig, K. (2014). Losing ground-Swedish life expectancy in a comparative perspective. PloS ONE, 9(2), Article e88357. https://doi.org/10.1371/journal. pone. 0088357 
Drefahl, S., Wallace, M., Mussino, E., Aradhya, S., Kolk, M., Brandén, M., Malmberg, B., and Andersson, G. (2020). A population-based cohort study of socio-demographic risk factors for COVID-19 deaths in Sweden. Nature Communications, 11, Article 5097. https://doi.org/10.1038/s41467-020-18926-3

Eayres, D., and Williams, E. S. (2004). Evaluation of methodologies for small area life expectancy estimation. Journal of Epidemiology and Community Health, 58(3), 243-249. https://doi.org/10.1136/jech.2003.009654

Gardner, J. W., and Sanborn, J. S. (1990). Years of potential life lost (YPLL)—what does it measure? Epidemiology, 1(4), 322-329. https://doi.org/10.1097/00001648-19900700000012

Goldstein, J. R., and Lee, R. D. (2020). Demographic perspectives on the mortality of COVID-19 and other epidemics. Proceedings of the National Academy of Sciences, 117(36), 22035-22041. https://doi.org/10.1073/pnas.2006392117

Indseth, T., Grøsland, M., Arnesen, T., Skyrud, K., Kløvstad, H., Lamprini, V., Telle, K., and Kjøllesdal, M. (2020). COVID-19 among immigrants in Norway, notified infections, related hospitalizations and associated mortality: A register-based study. Scandinavian Journal of Public Health, 49(1), 45-56. https://doi.org/10.1177/1403494820984026

Islam, N., Shkolnikov, V. M., Acosta, R. J., Klimkin, I., Kawachi, I., Irizarry, R. A., Alicandro, G., Khunti, K., Yates, T., Jdanov, D. A. et al. (2021). Excess deaths associated with COVID-19 pandemic in 2020: Age and sex disaggregated time series analysis in 29 high income countries. BMJ, 373, Article n1137. https://doi.org/10.1136/bmj.n1137

Ludvigsson, J. F. (2020). The first eight months of Sweden's COVID-19 strategy and the key actions and actors that were involved. Acta Paediatrica, 109(12), 2459-2471. https://doi.org/10.1111/apa.15582

Martinez, R., Soliz, P., Caixeta, R., and Ordunez, P. (2019). Reflection on modern methods: Years of life lost due to premature mortality-A versatile and comprehensive measure for monitoring non-communicable disease mortality. International Journal of Epidemiology, 48(4), 1367-1376. https://doi.org/10.1093/ije/dyy254

Modig, K., Ahlbom, A., and Ebeling, M. (2021a). Excess mortality from COVID-19: Weekly excess death rates by age and sex for Sweden and its most affected region. European Journal of Public Health, 31(1), 17-22. https://doi.org/10.1093/eurpub/ckaa218

Modig, K., Ahlbom, A., Lambe, M., and Ebeling, M. (2021b). Excess mortality for men and women above age 70 according to level of care during the first wave of COVID-19 pandemic in Sweden: A population-based study. The Lancet Regional Health - Europe, 4, Article 100072. https://doi.org/10.1016/j.lanepe.2021.100072

Modig, K., Ahlbom, A., and Matthews, A. (2020). Total mortalitet bättre vid jämförelser än död i COVID-19. Läkartidningen, 117, F3XL.

National Board of Health and Welfare. (2020a). Beskrivning av datakällor för avlidna i COVID-19 [description of data sources for COVID-19 deaths]. (Dnr. 6.7-14923/2020).

National Board of Health and Welfare. (2020b). Halvering av andelen döda bland dem som sjukhusvårdats för COVID-19 [50\% decrease in deaths among those hospitalized for COVID 19]. Pressmedelande, 24 November 2020. https://www.socialstyrelsen. se/om-socialstyrelsen/pressrum/press/halvering-av-andelen-doda-bland-dem-som-sjuk husvardats-for-covid-19/. 
National Board of Health and Welfare. (2021). Jämförelse av Socialstyrelsens och Folkhälsomyndigetens statistik över avlidna i COVID-19 under april och december [comparision of the National Board of Health and Welfare's, and the Public Helath Agency's statistics on COVID-19 deaths]. (Dnr: 6.7-7387/2021).

Pifarré i Arolas, H., Acosta, E., López-Casasnovas, G., Lo, A., Nicodemo, C., Riffe, T., and Myrskylä, M. (2021). Years of life lost to COVID-19 in 81 countries. Scientific reports, 11(1), 3504. https://doi.org/10.1038/s41598-021-83040-3

Public Health Agency. (2021a). Beskrivning av datakällor för övervakning av COVID-19 [description of data sources for monitoring COVID-19]. https://www. folkhalsomyndighetenglobalassets/statistik-uppfoljning/smittsamma-sjukdomar/veckor apporter-covid-19/2020/overvakningssystem-for-covid-19-v4.pdf

Public Health Agency. (2021b). Veckorapport om COVID-19, vecka 8 [Weekly report of COVID-19, week 8]. https://www.folkhalsomyndigheten.se/globalassets/ statistik-uppfoljning/smittsamma-sjukdomar/veckorapporter-covid-19/2021/covid-19veckorapport-2021-vecka-8.pdf

Quast, T., Andel, R., Gregory, S., and Storch, E. A. (2020). Years of life lost associated with COVID-19 deaths in the United States. Journal of Public Health, 42(4), 717-722. https://doi.org/10.1093/pubmed/fdaa159

Rostila, M., Cederström, A., Wallace, M., Brandén, M., Malmberg, B., and Andersson, G. (2021). Disparities in COVID-19 deaths by country of birth in Stockholm, Sweden: A total population based cohort study. American Journal of Epidemiology, 190(8), 1510-1518. https://doi.org/10.1093/aje/kwab057

Scherbov, S., and Ediev, D. (2011). Significance of life table estimates for small populations: Simulation-based study of estimation errors. Demographic Research, 24, 527-550. https: //doi.org/10.4054/DemRes.2011.24.22

Simons, G. (2020). Swedish government and country image during the international media coverage of the coronavirus pandemic strategy: From bold to pariah. Journalism and Media, 1(1), 41-58. https://doi.org/10.3390/journalmedia1010004

Short-term Mortality Fluctuations (STMF) data series. (2021). University of California, Berkeley (USA), and Max Planck Institute for Demographic Research (Germany). Available at www.mortality.org or www.humanmortality.de

Sprung, C. L., Joynt, G. M., Christian, M. D., Truog, R. D., Rello, J., and Nates, J. L. (2020). Adult ICU triage during the coronavirus disease 2019 Pandemic: Who will live and who will die? Recommendations to improve survival. Critical care medicine, 48(8), 1196-1202. https://doi.org/10.1097/ccm.0000000000004410

Statistics Sweden (2018). Sveriges framtida befolkning 2018-2070. [the future population of Sweden 2020-2070]. Demografiska Rapporter, 2018, 1.

Statistics Sweden (2020a). Sveriges framtida befolkning 2020-2070. [the future population of Sweden 2020-2070] Statistiska Meddelanden BE 18 SM 2001.

Statistics Sweden (2020b). Kohortdödligheten i Sverige. Dödlighetsutvecklingen fram till 2019. Demografiska Rapporter, 2020, 3.

Trias-Llimós, S., Riffe, T., and Bilal, U. (2020). Monitoring life expectancy levels during the COVID-19 pandemic: Example of the unequal impact of the first wave on Spanish regions. PloS ONE, 15(11), Article e0241952. https://doi.org/10.1371/journal.pone.0241952 
Vanthomme, K., Gadeyne, S., Lusyne, P., and Vandenheede, H. (2021). A population-based study on mortality among Belgian immigrants during the first COVID-19 wave in Belgium. Can demographic and socioeconomic indicators explain differential mortality? SSMPopulation Health, 14, Article 100797. https://doi.org/10.1016/j.ssmph.2021.100797

Wilmoth, J. R., Deegan, L. J., Lundström, H., and Horiuchi, S. (2000). Increase of maximum life-span in Sweden, 1861-1999. Science, 289(5488), 2366-2368. https://doi.org/10.1126/ science.289.5488.2366

\section{Appendix}

\section{Comparisons between different measures of COVID-19 mortality}

Our analysis is based on four different mortality statistics: the average number of deaths in 2017-2019, the number of deaths in 2020, the number of deaths according to Statistics Sweden's forecast for 2020, and the number of deaths related to COVID-19 according to the Swedish Public Health Agency's monitoring system SmiNet. The National Board of Health and Welfare (Socialstyrelsen) produces official statistics on causes of death that can also be used to estimate COVID-19 mortality. With the help of microdata on deaths in Sweden provided by the National Board of Health and Welfare, we have been able to make supplementary estimates of mortality for different months of 2020 based on data from different sources. We have compared the mortality rates for April and December, which were the two months with the highest mortality levels in 2020.

The Public Health Agency's estimates of deaths are linked to testing (Public Health Agency, 2021a). Tests were performed more frequently in late 2020 than in the spring of that year. This could mean that there was some under-reporting of COVID-19 when tests were less frequent at the beginning of the year, and that there was over-reporting of COVID-19 when tests were performed more extensively at the end of the same year (because people who died from other causes, but who had a positive COVID-19 test result, may have been included in the SmiNet statistics). The Public Health Agency (2021a) has previously described differences in the reporting of deaths in different data sources. The National Board of Health and Welfare (2021) has noted that at the end of 2020, slightly more COVID-19 deaths were reported in the Public Health Agency data than in the National Board of Health and Welfare statistics.

In Figure A.1, we show the excess mortality estimates for a spring month and a winter month in 2020 with high mortality compared to the COVID-19-related mortality estimates based on data from the Public Health Agency's SmiNet data and the National Board of Health and Welfare, respectively, for different age groups. In general, we see that the different mortality measures are quite similar. For April, the Swedish Public Health Agency's definition is slightly below the definition based on causes of death, and is also below our measure based on excess mortality. This is probably because SmiNet underestimated COVID-19 mortality to some extent 
during the beginning of the epidemic due to lower testing (Public Health Agency, 2021a). The total number of COVID-19 deaths for 2020 is 9,816 based on the data from SmiNet is, while it is 10,256 based on our summary of data from the cause-ofdeath register.

For December, we see the opposite pattern, as the number of COVID-19 deaths according to the Swedish Public Health Agency's definition is slightly higher than when COVID-19 deaths are defined according to registered causes of death. For women in December, both data sources' measures of COVID-19 mortality exceed our measure of excess mortality. For men in April, we see some excess mortality at ages 70-79 that is not visible in the data on COVID-19 deaths from the Swedish Public Health Agency or from the National Board of Health and Welfare. Our data do not allow us to examine in more detail why the different data sources deviate slightly from each other over the year.

Overall, however, we note that the measures of COVID-19 deaths based on both the Public Health Agency's and the National Board of Health and Welfare's definitions correspond well with our measures of excess mortality in 2020. We therefore believe that our study describes the patterns of COVID-19 mortality during the year reasonably well. 
Figure A.1:

Number of deaths in April and December 2020 for men and women in different age groups. Excess mortality compared to 2017-2019, COVID-19 deaths according to the Public Health Agency's SmiNet, and COVID-19 deaths according to the cause-of-death register of the National Board of Health and Welfare
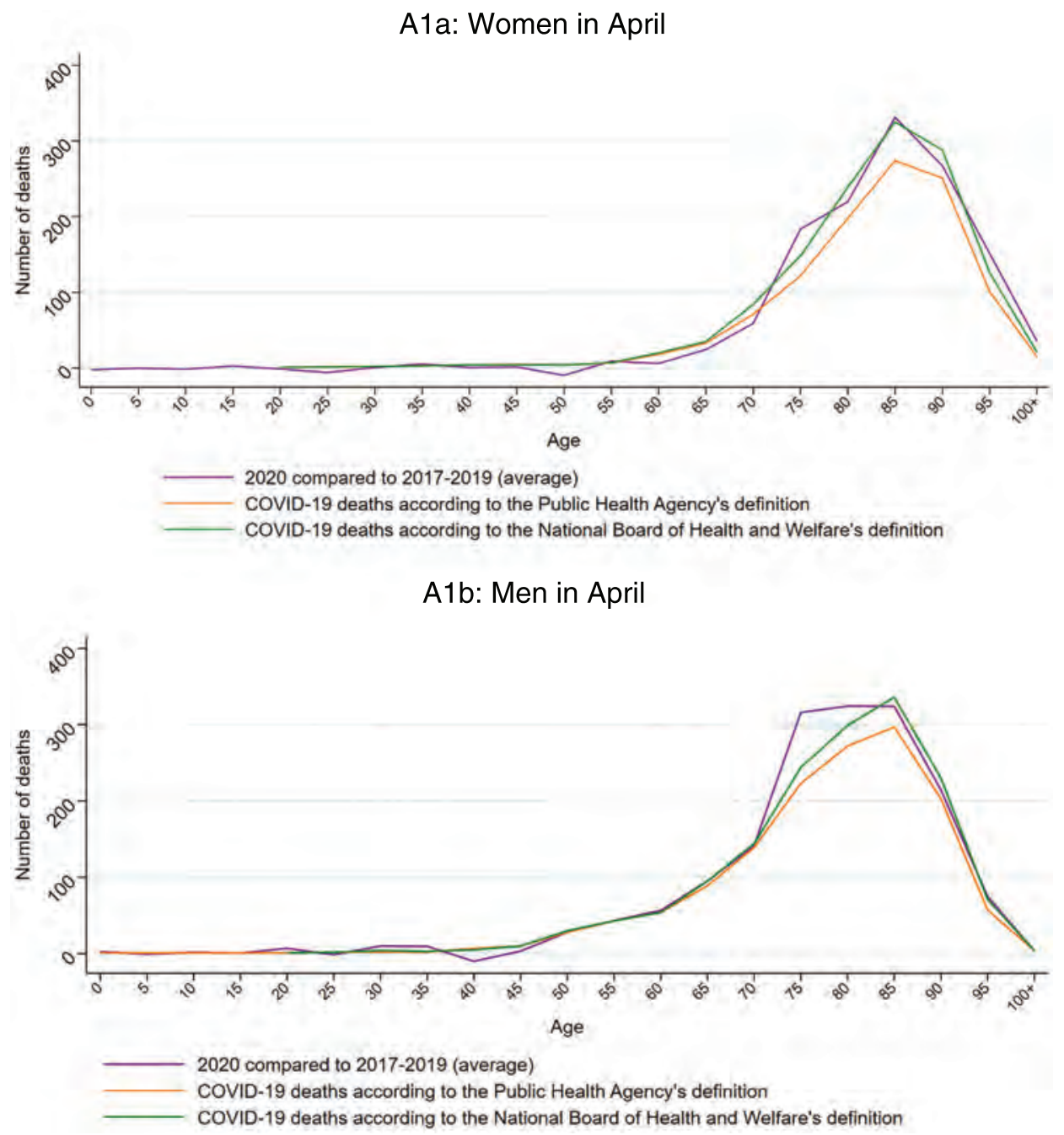
Figure A.1:

Continued

\section{A1c: Women in December}

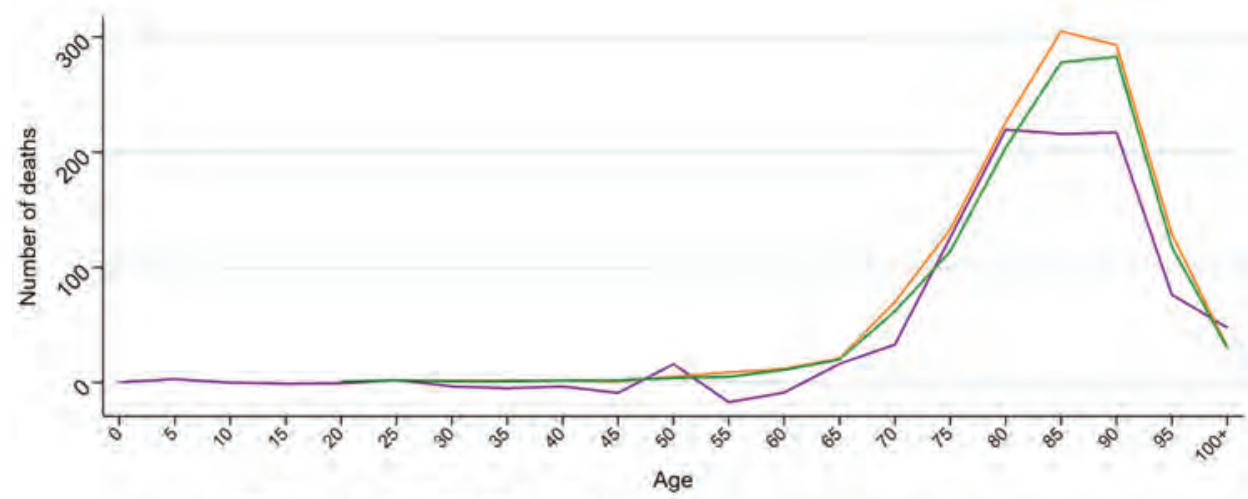

2020 compared to $2017-2019$ (average)

COVID-19 deaths according to the Public Health Agency's definition

COVID-19 deaths according to the National Board of Health and Welfare's definition

\section{A1d: Men in December}

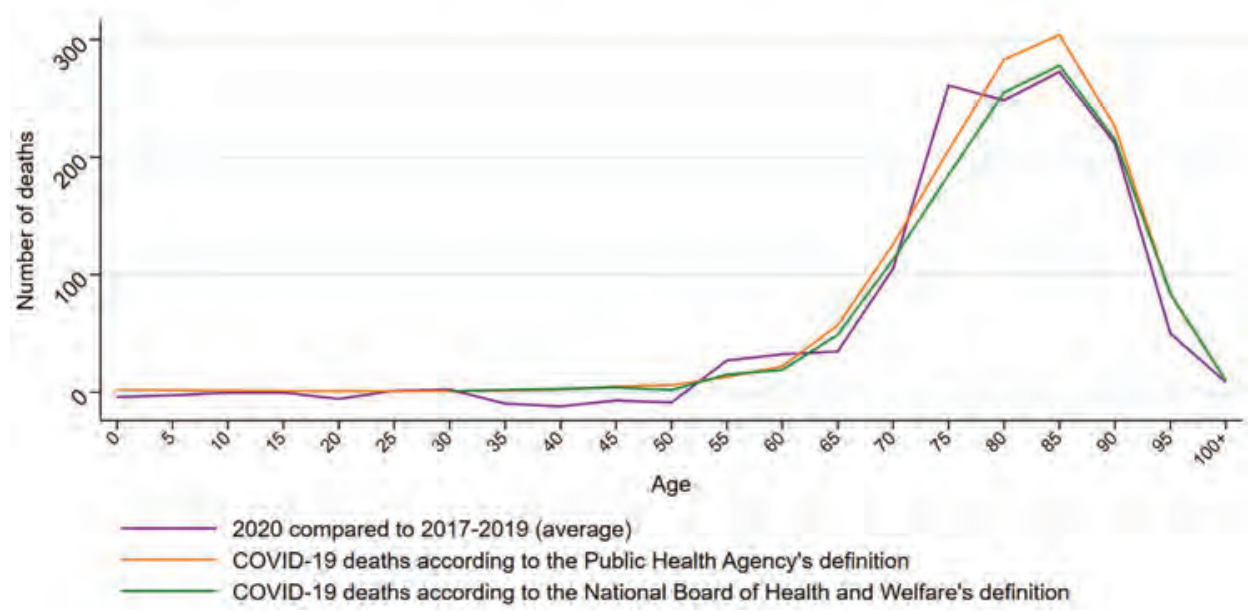

Open Access This article is published under the terms of the Creative Commons Attribution 4.0 International License (https://creativecommons.org/licenses/by/4.0/) that allows the sharing, use and adaptation in any medium, provided that the user gives appropriate credit, provides a link to the license, and indicates if changes were made. 